\title{
ZEBRAFISH GPR161 CONTRIBUTES TO BASAL HEDGEHOG REPRESSION IN A TISSUE-SPECIFIC MANNER
}

\author{
Philipp Tschaikner ${ }^{1,2}$, Dominik Regele ${ }^{1}$, Willi Salvenmoser ${ }^{3}$, Stephan Geley ${ }^{4}$, Eduard Stefan², Pia \\ Aanstad $^{1}$ \\ ${ }^{1}$ Institute of Molecular Biology and Center for Molecular Biosciences, University of Innsbruck, \\ Innsbruck, Austria \\ ${ }^{2}$ Institute of Biochemistry and Center for Molecular Biosciences, University of Innsbruck, Innsbruck, \\ Austria
}
${ }^{3}$ Institute of Zoology and Center of Molecular Bioscience Innsbruck, University of Innsbruck, Innsbruck, Austria

${ }^{4}$ Division of Molecular Pathophysiology, Medical University of Innsbruck, Innsbruck, Austria

*Corresponding author: Pia.Aanstad@uibk.ac.at

\begin{abstract}
Hedgehog $(\mathrm{Hh})$ ligands act as morphogens to direct patterning and proliferation during embryonic development. Protein kinase A (PKA) is a central negative regulator of $\mathrm{Hh}$ signalling, and in the absence of $\mathrm{Hh}$ ligands, PKA activity prevents inappropriate expression of $\mathrm{Hh}$ target genes. The $\mathrm{G}_{\alpha s^{-}}$ coupled receptor Gpr161 contributes to the basal Hh repression machinery by activating PKA, although the extent of this contribution is unclear. Here we show that loss of Gpr161 in zebrafish leads to constitutive activation of low-, but not high-level Hh target gene expression in the neural tube. In contrast, in the myotome, both high- and low-level Hh signalling is constitutively activated in the absence of Gpr161 function. Our results suggest that the relative contribution of Gpr161 to basal repression of $\mathrm{Hh}$ signalling is tissue-specific. Distinct combinations of $\mathrm{G}$-protein-coupled receptors may allow the fine-tuning of PKA activity to ensure the appropriate sensitivity to $\mathrm{Hh}$ across different tissues.
\end{abstract}




\section{Introduction}

The Hh signalling pathway is a key regulator of cell fate specification and proliferation during embryonic development, and plays important roles in adult tissue homeostasis (Briscoe and Thérond, 2013; Ingham et al., 2011). Dysregulation of Hh signalling can lead to the formation of common and severe forms of human cancers such as basal cell carcinoma and medulloblastoma (Jiang and Hui, 2008; Raleigh and Reiter, 2019).

When Hh ligands bind their receptor Patched (Ptch), the inhibition of Smo by Ptch is alleviated, and Smo localises to the primary cilium (Corbit et al., 2005), where it activates downstream signalling to regulate the activity of the bifunctional Gli transcription factors.

Hh ligands act as morphogens, and the transcriptional outcome of Hh signalling is determined by the balance between repressor and activator forms of the Gli transcription factors. This balance is controlled by the activity of PKA and other kinases (Hui and Angers, 2011; Niewiadomski et al., 2019). In the absence of $\mathrm{Hh}$, the basal $\mathrm{Hh}$ repression machinery is thought to maintain a high level of PKA activity. PKA phosphorylates the Gli proteins and primes them for further phosphorylation and proteolytic cleavage, to yield truncated forms that act as transcriptional repressors (GliR) (Niewiadomski et al., 2014; Pan et al., 2009; Wang et al., 2000). In addition, PKA also plays a role in restricting the activity of full length Gli (GliA) by promoting its association with Sufu (Humke et al., 2010; Marks and Kalderon, 2011). Low levels of exposure to Hh ligands blocks the formation of GliR, whereas high levels of $\mathrm{Hh}$ exposure is required for the formation of the activator forms of Gli. This is thought to be controlled through a cluster of six PKA target residues in Gli, with distinct phosphorylation patterns regulating the formation of repressor and activator forms (Niewiadomski et al., 2014). This rheostat mechanism ensures that the level of Gli transcriptional activity corresponds to the level of PKA activity, which in turn must be controlled by the level of Smo activity and Hh ligand exposure (Niewiadomski et al., 2019, 2014). Consistent with this, a complete loss of PKA activity leads to constitutive (Smo-independent) maximal Hh signalling, whereas constitutive activation of PKA abolishes all Hh-dependent transcription (Hammerschmidt et al., 1996; Tuson et al., 2011; Zhao et al., 2016).

A central and long-standing question in $\mathrm{Hh}$ signalling regards the nature and regulation of the basal repression machinery and the mechanism of regulation. In Drosophila, Smo has been shown to regulate PKA activity directly by activating $G_{\alpha i}$-proteins to modulate cAMP levels (Ogden et al., 2008). Although vertebrate Smo can also couple to $G_{\alpha i}$ (Riobo et al., 2006), it is clear that $G_{\alpha i}$ is not required for all aspects of vertebrate Hh signalling (Ayers and Thérond, 2010), raising the question which other mechanisms contribute to the regulation of PKA. 
The murine orphan G-protein coupled receptor (GPCR) Gpr161 contributes to basal Hh repression by activating $G_{\alpha s}$ and consequently PKA (Mukhopadhyay et al., 2013). In the absence of Hh ligands, Gpr161 localises to the primary cilia, and is removed from the cilia upon activation of Smo (Mukhopadhyay et al., 2013; Pal et al., 2016). These results suggest that Gpr161 maintains PKA activity in the cilium in the absence of $\mathrm{Hh}$, and that the ciliary exit of Gpr161 is required for $\mathrm{Hh}$ signalling and the reduction of PKA activity (Mukhopadhyay et al., 2013; Pal et al., 2016). However, Gpr161 has also been shown to be a substrate of PKA, and can act as an A kinase anchoring protein (Bachmann et al., 2016; Torres-Quesada et al., 2017). Thus, the exact molecular mechanisms that regulate Gpr161 activity in the context of Hh signalling remain unclear.

Gpr161 mutants display severe developmental malformations, including craniofacial defects and ventralisation of the neural tube, that were independent of Smo function, suggesting that Gpr161 causes constitutive activation of downstream Hh signal transduction (Mukhopadhyay et al., 2013). However, the neural tube of Gpr161 mutants was less severely ventralised than that observed in embryos completely lacking PKA activity (Tuson et al., 2011). In neural progenitor cells (NPCs), Gpr161 was found to be epistatic to Smo only for low level signalling, while expression of high level targets such as Nkx2.2 and FoxA2 still depended on Smo function (Pusapati et al., 2018), suggesting that in the neural tube, Gpr161 plays an important role in controlling basal and low level Hh signalling activity. In murine NIH 3T3 fibroblasts, loss of Gpr161 does not affect basal repression, although the mutant cells displayed an increased sensitivity to Hh ligands. Taken together, these results suggest that additional $\mathrm{G}_{\alpha s}$-coupled receptors may be involved in maintaining PKA activity in the absence of Hh ligands (Pusapati et al., 2018). Supporting this, several studies have identified additional GPCRs that regulate Hh signalling in parallel or downstream of Smo (Klein et al., 2001; Singh et al., 2015; Stückemann et al., 2012).

To facilitate the study of Gpr161 in Hh signalling during development, we have generated zebrafish gpr161 mutants, and show that Gpr161 is an important negative modulator of Hh signalling in zebrafish embryos. We find that in the zebrafish neural tube, Gpr161 is epistatic to Smo for low-level Hh targets, however the activation of high-level targets depends on Smo activity in gpr161 mutants. Interestingly, in the myotome, both high and low levels of Hh signalling are independent of Smo function, suggesting that several GPCRs may be involved in regulating PKA activity during $\mathrm{Hh}$ signalling, and that the level of contribution of Gpr161 to basal repression of Hh signalling is tissuespecific. 


\section{Results}

Gpr161 is an evolutionary conserved GPCR with two paralogs in zebrafish

The zebrafish genome contains two conserved paralogs of Gpr161, Gpr161a and Gpr161b, with 71\% sequence identity and $84 \%$ sequence similarity between each other, and more than $70 \%$ similarity to the murine Gpr161 protein (Figure 1A, Figure 1 Supplement 1). Expression analysis using qRT-PCR showed that both transcripts are expressed during embryonic development, but while gpr161b is maternally provided, gpr161a expression is first detected at 9 hours post fertilisation (hpf) (Figure 1B). In mouse, Gpr161 localises to primary cilia, and this localisation has been proposed to be important for its role in modulating the Hh signalling pathway (Mukhopadhyay et al., 2013; Pal et al., 2016; Shimada et al., 2018). To test whether zebrafish Gpr161 also localise to primary cilia, we injected mRNA of Myc-tagged versions of Gpr161a and Gpr161b into one-cell stage zebrafish embryos. Both Gpr161a and Gpr161b were readily detected at primary cilia in gastrula stage zebrafish embryos (Figure 1C).

Gpr161a and Gpr161b are functionally redundant but essential during zebrafish embryonic development

To investigate the functional roles of Gpr161a and Gpr161b during zebrafish development, we used CRISPR/cas9 to generate mutant alleles for each gene, $g p r 161 a^{m / 200}$, which carries a $6 \mathrm{bp}$ insertion in the second coding exon of gpr161a, and gpr161 $b^{m / 201}$, harboring an 8bp deletion in the second coding exon of gpr161b. Both alleles introduce premature stop codons within the 7-transmembrane-domain region of the respective proteins, and are predicted to be functionally inactive (Figure 1 Supplement 2). Animals homozygous for either $g p r 161 a^{m / 200}$ or gpr161 $b^{\text {m/201 }}$ alone, or animals lacking three of the four gpr161 alleles, showed no effect either on embryonic development or in adult viability and fertility. In contrast, gpr161a; gpr161b double zygotic homozygous mutant embryos showed clear morphological phenotypes by $24 \mathrm{hpf}$, suggesting that Gpr161a and Gpr161b act in a functionally redundant manner (Figure 2A). To determine the contribution of maternal Gpr161b, we generated embryos from incrosses of $\mathrm{gpr} 161 \mathrm{~b}^{-/} ; \mathrm{gpr} 161 \mathrm{a}^{+/-}$animals. Quantitative analysis of gpr161a expression at the 2 cell stage of these MZgpr161b; gpr161a mutant embryos showed that a complete loss of Gpr161b did not result in a compensatory maternal upregulation of Gpr161a (Figure 2 Supplement 1). We conclude that MZgpr161 $b^{-1} ;$ gpr161 $a^{-/-}$mutant embryos are likely to represent a complete loss of function of zebrafish Gpr161, and refer to these mutants as gpr161 mutants below.

At 24hpf, gpr161 mutant embryos display several developmental abnormalities, including malformed eyes lacking any obvious lens or retinal structure (Figure 2A). At this stage of development, wildtype embryos display chevron shaped somites, while the somites of gpr161 mutants have a more obtuse angle (Figure 2A). These phenotypes, which are only present in the double mutant line, but not in 


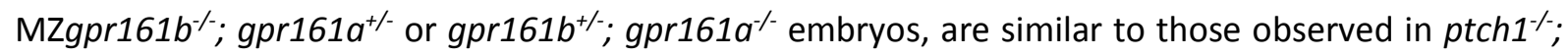
ptch $2^{-/}$double mutant embryos (Koudijs et al., 2008). In contrast to $p t c h 1^{-1} ;$ ptch $2^{-/}$double mutant embryos which lack eyes (Koudijs et al., 2008), a rudimentary eye can be identified in gpr161 mutants at $72 \mathrm{hpf}$ (Figure 2B).

At this stage, the retina of wild type embryos is organised into six evolutionarily conserved layers: the pigmented epithelium, the photoreceptor cell layer, the outer plexiform layer, the inner nuclear layer, the inner plexiform layer, and the ganglion cell layer (Schmitt and Dowling, 1999). Semi-thin sectioning revealed that while eye morphogenesis was abnormal, remnants of all six layers were clearly identified by morphology (Figure 2D, Figure 2 Supplement 2A). However, these layers are not well separated and the optic cup is partially folded (Figure 2 Supplement 2B). Additionally, remnants of a forming lens can be found in gpr161 mutant embryos (Figure 2 Supplement 2A). A striking phenotype of the gpr161 mutants is the complete loss of jaw structures (Figure 2B), as demonstrated by scanning electron microscopy (SEM) imaging, which revealed that gpr161 mutant embryos display an open pharynx with a complete lack of all jaw structures (Figure 2C). While ptch1\%; ptch $2^{-/}$double mutant embryos were reported to lack all olfactory structures (Koudijs et al., 2008), SEM imaging revealed that in the gpr161 mutants the olfactory pits are present, though severely reduced in size (Figure 2C).

Zebrafish embryos with a strong $\mathrm{Hh}$ gain-of-function phenotype, such as the $p t c h 1^{-/}$; $p t c h 2^{-/}$double mutants, also display defects in the development of the otic vesicles (Koudijs et al., 2008). The gpr161 mutant embryos exhibited smaller otic vesicles compared to wild type embryos (Figure 2B). Serial sections of the otic vesicles revealed the absence of the dorsolateral septum (Figure 2 Supplement 2C). The combination of developmental defects in ocular and otic structures is commonly seen in mutants of negative regulators of Hh signalling, such as sufu, ptch1 and hhip (Whitfield et al., 1996), and suggests that Gpr161 acts to negatively regulate Hh signalling also in zebrafish.

Gpr161 mutant mice do not form limb buds (Hwang et al., 2018; Mukhopadhyay et al., 2013) and ptch1\%; ptch $2^{-\%}$ double mutant zebrafish embryos lack pectoral fin buds (Koudijs et al., 2008). In contrast to the requirement for Gpr161 in murine limb formation, pectoral fin formation appeared normal in the zebrafish gpr161 mutant embryos. (Figure 2B, Figure 2 Supplement 2D). The morphological phenotypes observed in gpr161 mutants are consistent with increased $\mathrm{Hh}$ signalling. To determine whether Hh signalling is upregulated in gpr161 mutants, we assessed the expression of known Hh target genes in the neural tube by qRT-PCR and RNA in situ hybridisation. 
pax7a, which is repressed by Hh signalling (Guner and Karlstrom, 2007), was strongly downregulated in gpr161 mutant compared to wild type embryos (Figure 3B). RNA in situ hybridisation revealed that expression of shha, the major Hh ligand expressed in the neural plate was not expanded in gpr161 mutants (Figure $3 \mathrm{~A}$ ). However, expression of ptch2, a direct transcriptional target of th signalling (Concordet et al., 1996), was expanded in gpr161 mutants (Figure 3A), suggesting that Hh signalling is upregulated in gpr161 mutants downstream of Shh expression. Similarly, expression of olig2, a marker of motor neuron induction which depends on low-level Hh activity (Dessaud et al., 2007; Park et al., 2002), as well as $n k x 2.2 a$, a marker for V3 interneuron progenitor cells of the lateral floorplate (Barth and Wilson, 1995; Briscoe et al., 1999), were clearly expanded in the gpr161 mutant neural tube (Figure $3 \mathrm{~A}$ ). We note that the expansion of the low-level target olig2 appears to be stronger than the expansion of the high-level target $n k x 2.2 a$ (Figure $3 \mathrm{~A}$ ). Taken together, these results show that loss of Gpr161 leads to a hyperactivation of the Hh signalling pathway in zebrafish.

In the zebrafish myotome, sustained Hh signalling during gastrulation and somitogenesis stages have been shown to be required for the specification of several cell types, including Prox1 and Eng double positive muscle pioneer cells (MPs) and Prox1 positive superficial slow fibres (SSFs) (Wolff et al., 2003). While medium-to-low level Hh signalling is sufficient for the specification of SSFs, the formation of MPs requires high levels of Hh (Wolff et al., 2003). Consistent with the expansion of Hh target genes in the neural tube, gpr161 mutants also displayed an increase in both SSFs and MPs (Figure 3C). While zygotic Gpr161 loss of function resulted in a significant increase in both SSFs (from $22 \pm 2$ (mean $\pm S D$ ) in wt to $33 \pm 5$ in zygotic gpr161 mutants) and MPs (from $4 \pm 1$ (mean $\pm S D$ ) in wt to $7 \pm 2$ in zygotic gpr161 mutants), complete loss of both maternal and zygotic Gpr161 led to a stronger increase in both SSFs and MPs (56 \pm 9 (mean \pm s.d.) SSFs, and $23 \pm 10 \mathrm{MPs}$ ), consistent with the requirement for sustained Hh signalling in muscle cell development (Wolff et al., 2003). These results suggest that in the somites, loss of Gpr161 results in expansion of both high and low Hh signalling targets.

\section{gpr161 mutants remain sensitive to Shh}

Our results suggest that although loss of Gpr161 function in zebrafish leads to increased Hh signalling activity, gpr161 mutants display weaker phenotypes than those seen in mutants with maximal activation of Hh signalling. To determine whether Hh signalling could be further activated in gpr161 mutants in response to $\mathrm{Hh}$, we injected 50 or $100 \mathrm{pg}$ sh mRNA, and assessed SSF and MP formation using Prox1 and Eng antibody staining as above (Figure 4A-B). In wild-type embryos, overexpression of $100 \mathrm{pg}$ shh resulted in an approximate 1.8-fold increase in both MPs and SSFs (Figure 4B), a significant change from uninjected control embryos (ANOVA, SSFs $p<0.01$, MPs $p<0.01$ ). In contrast, neither 50 nor 100 pg shh resulted in a significant increase in the number of SSFs in gpr161 mutant 
embryos (ANOVA, $50 \mathrm{pg} p>0.9,100 \mathrm{pg} p>0.5$ ), suggesting that the number of SSFs have reached a maximum level in the uninjected mutants. Injection of $100 \mathrm{pg}$ sh did, however, give a significant 1.9fold increase in the number of MPs in gpr161 mutant embryos (ANOVA, $p<0.001$ ) (Figure 4B). Taken together, these results suggest that in the gpr161 mutant, medium-to-low level Hh signalling targets are activated close to maximal levels, whereas high level targets of Hh signalling are increased, but not maximally so.

\section{Activation of PKA rescues gpr161 mutant phenotypes}

Murine Gpr161 was proposed to act as a constitutively active $G_{\alpha s}$-coupled receptor, which contributes to maintain basal levels of PKA activity to keep the Hh pathway inactive (Mukhopadhyay et al., 2013). This model predicts that the phenotypes observed in the gpr161 mutants are due to a loss of adenylate cyclase activity, and should be rescued by artificial activation of adenylate cyclase by agents such as forskolin. Previous studies have reported that $300 \mu \mathrm{M}$ forskolin phenocopies a complete loss of Hh signalling (Barresi et al., 2000). Consistent with this, treatment with $300 \mu \mathrm{M}$ forskolin resulted in a near complete loss of all MPs and SSFs in wild-type as well as gpr161 mutant embryos (Figure 5A-B), consistent with the model that hyperactivation of Hh signalling in the gpr161 mutants is due to a reduction of PKA activity. Treatment with lower concentrations of forskolin, ranging from $500 \mathrm{nM}$ to $50 \mu \mathrm{M}$, had only minor effects on somite development of wild-type embryos, but resulted in a significant degree of rescue of the gpr161 mutant phenotype (Figure 5A-B). We note that MPs, which require high levels of Hh signalling, were more sensitive to forskolin concentrations than SSFs, which require low levels of $\mathrm{Hh}$.

Distinct contributions of Gpr161 to basal repression of $\mathrm{Hh}$ signalling in different tissues

To determine the epistatic relationship between Smo and Gpr161 in zebrafish, we used the zebrafish

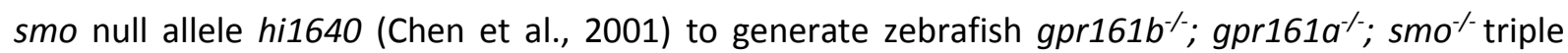
mutants, and assessed Hh signalling activity using Prox1/Eng staining and neural tube markers, as above. Zebrafish $\mathrm{gpr} 161 \mathrm{~b}^{-/} ; \mathrm{gpr} 161 \mathrm{a}^{- \text {; }} \mathrm{smo}^{-/}$triple homozygous mutant embryos showed a morphological phenotype, as well as an expansion of both SSFs and MPs, that were indistinguishable from gpr161 $b^{-/}$; gpr161 $1 a^{-/}$double homozygous mutant embryos (Figure 6A-B, Figure 6 Supplement 1), consistent with the reported phenotypes in the mouse Gpr161;Smo double mutants (Mukhopadhyay et al., 2013). Further, the expansion of low-level Hh target-genes ptch2 and olig2 was similarly found to be independent of Smo function (Figure 6C). In contrast, the double mutant gpr161\%; gpr161 $\mathrm{a}^{-/}$; $\mathrm{smo}^{-/}$triple mutant embryos showed no detectable $n k \times 2.2 a$ expression, suggesting that in the neural tube, though not in the somites, high level Hh target gene expression is dependent on Smo function in the absence of Gpr161. 


\section{Discussion}

Hh signalling is tightly controlled at multiple levels in order to accurately translate morphogen gradients into graded transcriptional responses mediated by the Gli transcription factors. PKA both promotes formation of the Gli repressor forms and inhibits Gli activator forms, thereby controlling sensitivity to Hh ligands, and providing a filter for Hh signalling strength. How PKA activity is finetuned in Hh signalling is not completely understood. GPCRs such as Gpr161 have been shown to impact on Hh signalling by regulating PKA via the regulation of adenylate cyclase activity. To extend our understanding of how GPCRs regulate Hh signalling, we generated zebrafish gpr161 mutants and analysed $\mathrm{Hh}$-dependent signalling in the neural tube and the myotome.

The zebrafish genome contains two conserved Gpr161 orthologues, Gpr161a and Gpr161b. We have generated mutants for both orthologues, and show that Gpr161a and Gpr161b act redundantly in early zebrafish development. Zebrafish mutants lacking Gpr161 function show an expansion of $\mathrm{Hh}$ target gene expression both in the neural tube and in the somites, and develop severe craniofacial defects that are similar to those described for the $p t c 1 \%$; ptc2 ${ }^{-}$- double mutants (Koudijs et al., 2008). These results confirm that the role of Gpr161 as a modulator of Hh signalling is conserved in the vertebrate lineage.

Gpr161 was proposed to contribute to the basal Hh repression machinery by activating $\mathrm{G}_{\alpha \mathrm{s}}$ and adenylate cyclase, resulting in activation of PKA, and overexpression of murine Gpr161 was shown to lead to a general increase in intracellular cAMP levels (Mukhopadhyay et al., 2013). However, direct evidence for reduced cAMP production in Gpr161 mutant cells is hampered by the difficulties in measuring physiological cAMP levels in specific subcellular compartments such as the primary cilium. We have taken advantage of the zebrafish embryo's amenability to pharmacological treatments to further probe the mechanism of Gpr161 action. Consistent with the model that loss of Gpr161 leads to lowered cAMP levels and reduced PKA activity, we found that treatment with the CAMP elevating agent forskolin fully rescued muscle cell specification in the gpr161 mutant embryos. Interestingly, a 100 -fold concentration range $(0.5-50 \mu \mathrm{M})$ of forskolin gave very similar near-complete rescue of both mutant morphology and molecular read-outs of both high and low level Hh target gene expression in the somites, suggesting that additional mechanisms may be in place to ensure appropriate regulation of PKA activity in the presence of excess cAMP. Previous studies have reported that loss of Gpr161 may also affect other signalling pathways in addition to Hh signalling (Li et al., 2015; Mukhopadhyay et al., 2013). While we cannot rule out a role for Gpr161 in processes not related to Hh signalling, our results suggest that loss of Gpr161 function can be fully compensated by artificial activation of adenylate cyclase. 
A comparison of phenotypes suggests that the upregulation of Hh signalling in zebrafish gpr161

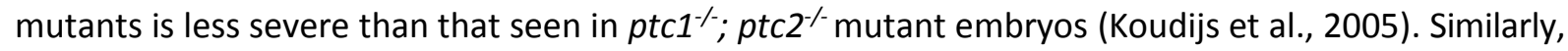
injection of a dominant-negative form of PKA resulted in an apparently stronger increase in Hhdependent muscle cell specification in the myotome than could observed in the gpr161 mutants (Zhao et al., 2016). This is consistent with data obtained in mice, where a loss of PKA or $\mathrm{G}_{\alpha s}$ leads to more severe ventralisation of the neural tube than what is observed in the Gpr161 mutants (Mukhopadhyay et al., 2013; Pusapati et al., 2018; Regard et al., 2013; Tuson et al., 2011). Further supporting the idea that Hh signalling is not maximally activated in the gpr161 mutants, we find that injection of shha mRNA can further increase high, but not low, level Hh targets in the somites of gpr161 mutants. Thus we conclude that whereas low level Hh signalling is maximally active in the gpr161 mutants, additional mechanisms contribute to PKA activation to control high level Hh signalling in the absence of Gpr161 function.

271 Importantly, we also show that low level Hh signalling in the neural tube of gpr161 mutants is independent of Smo, whereas expression of the high level Hh target gene $n k \times 2.2 a$ clearly requires Smo function. Our results are consistent with the model that $\mathrm{G}_{\alpha s}$-coupling and activation by $\mathrm{Gpr} 161$ is one of several mechanisms that contribute to the mobilisation of compartmentalised cAMP to repress Hh target activation, and that the reduction in CAMP levels caused by loss of Gpr161 is sufficient to cause constitutive, Smo-independent activation of low, but not high level Hh signalling. This result provides genetic evidence to support the model based on results from pharmacological inhibition of Smo in mammalian cell culture (Pusapati et al., 2018). Similar experiments were performed in the mouse Gpr161 mutant, with the conclusion that Gpr161 is largely epistatic to Smo (Mukhopadhyay et al., 2013). These authors do however note that the expression of high level Hh target genes, such as Nkx2.2 and FoxA2, is reduced in Smo; Gpr161 double mutants compared to Gpr161 single mutants. One possibility is that this difference is due to the different assays used to assess Hh target gene expression in mouse and zebrafish neural tubes. Whereas Mukhopadhyay and colleagues used immunohistochemistry to detect $\mathrm{Hh}$ target gene expression (Mukhopadhyay et al., 2013), our results are based on chromogenic in situ hybridisation, a far less sensitive assay. Thus, we can not rule out that some low level $n k x 2.2 a$ expression persists in the zebrafish triple mutants. Another possibility is that there could be species-specific differences in the roles of GliR and GliA and/or cAMP levels, or alternatively, Gpr161 may make a relatively larger contribution to cAMP levels in the zebrafish neural tube compared to mouse. Interestingly, we do observe tissue-specific differences in zebrafish in our epistasis experiments. In the gpr161 mutant myotome, both high and low level Hh signalling outcomes are independent of Smo, suggesting that in the somites Gpr161 is completely epistatic to Smo. We suggest that in the neural tube, additional unknown factors make significant contributions to promote basal cAMP levels, whereas in the zebrafish myotome, Gpr161 
alone may account for the largest part of the basal repression machinery. Thus, distinct combinations of GPCRs in different cell types can contribute to complex and tissue-specific regulation of $\mathrm{Hh}$ signalling. The identification of these additional GPCRs, as well as other factors that control PKA activity downstream of adenylate cyclases, will be required to understand how Hh signalling is finetuned to orchestrate the great variety of Hh-dependent biological processes in a cell type specific manner.

\section{Materials and Methods}

CRISPR/cas9 genome editing and genotyping

Guide RNAs for CRISPR/cas9 mediated knockout of both gpr161a (ENSDART00000151311.2) and gpr161b (ENSDART00000078051.6) were designed using the ChopChop web tool (Montague et al., 2014) and synthesised as described previously (Huang et al., 2014). Embryos were injected with 50 pg of gene specific sgRNA and 300pg of cas9 mRNA at 1-cell stage. F0 founder fish were identified by T7 Endonuclease I digests of gene-specific PCR products from pooled genomic DNA obtained from F1 offspring, following the manufacturer's protocol (NEB, \#M0302L). While the gpr161 $a^{\text {m/200 }}$ allele harbors an 8bp deletion, the introduced mutation in gpr161 ${ }^{\text {m/201 }}$ leads to a $6 \mathrm{bp}$ insertion, which were identified by running out gene specific PCR products (see Table 2) on 4\% agarose gels. Genotyping of the $s m o^{\text {hil640 }}$ allele was performed as described previously (Chung and Stainier, 2008).

\section{Zebrafish lines and husbandry}

All zebrafish lines including SAT wildtype strains were kept at $28^{\circ} \mathrm{C}$ according to standard protocols.

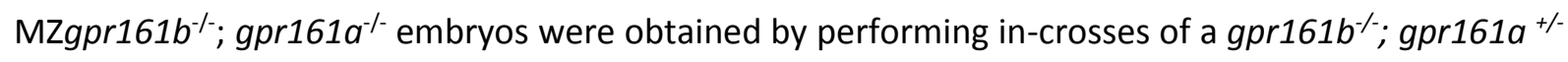
line. Embryos were raised at $28^{\circ} \mathrm{C}$ and staged by morphology (Kimmel et al., 1995).

All experimental protocols concerning zebrafish were approved by the Austrian Ministry for Science and Research (BMWFW-66.008/0016-WF/V/3b/2016, BMBWF-66.008/0015-V/3b/2018), and experiments were carried out in accordance with approved guidelines.

\section{Construction of plasmids}

To generate expression-vectors for gpr161a and gpr161b the coding sequence of both genes were amplified with overlapping primers (see Table 2) using homemade PfuX7 polymerase (Nørholm, 2010) and fused in-frame to a Myc-Tag into pCS2+ by in vivo Assembly (IVA) cloning (García-Nafría et al., 2016). 


\section{Quantitative (q) RT-PCR}

RNA was isolated from zebrafish embryos with Trizol (Ambion) following the manufacturer's instructions. RNA integrity was checked by agarose gel electrophoresis and the concentration was measured using a Nanodrop 2000c (Thermo) spectrophotometer.

Complementary DNA was transcribed from equal amounts of dsDNase-treated total RNA using the Maxima RT kit for qPCR (Thermo) with dsDNase according to the manufacturer's instructions.

RT-qPCRs were performed using 5x HOT FIREPol EvaGreen qPCR Supermix (Solis Biodyne) and contained each primer at 250nM and cDNA corresponding to a total RNA amount of $15 \mathrm{ng}$ for pooled embryos or $5 \mathrm{ng}$ for single embryos. PCRs were run on a CFX96 Connect (BioRad) under following conditions: $12 \min 95^{\circ} \mathrm{C}, 40$ cycles of $95^{\circ} \mathrm{C}$ for $30 \mathrm{~s}, 60^{\circ} \mathrm{C}$ for $30 \mathrm{~s}$ and $72^{\circ} \mathrm{C}$ for $20 \mathrm{~s}$. Melt curves were recorded from $65^{\circ} \mathrm{C}$ to $95^{\circ} \mathrm{C}$ in $0.5^{\circ} \mathrm{C}$ increments. Data was acquired using CFX Manager 3.1 (BioRad) and exported as RDML files for processing.

Data analysis was performed in $\mathrm{R}$ version 3.4.4. Fluorescence data were imported using the package RDML (Rödiger et al., 2017) and amplification curves fitted using the 'cm3' model (Carr and Moore, 2012) implemented in the package qpcR (Ritz and Spiess, 2008). The first derivative (d0) of the model was used as expression value. Expression values for genes of interest were normalised using the geometric mean of the expression values of the reference genes eef1aa and rpl13.

Whole-mount in situ hybridisation

In situ hybridisation was performed following standard protocols. DIG-labelled antisense probes were made for shha (Krauss et al., 1993), ptch2 (Concordet et al., 1996), olig2 (Park et al., 2002) and $n k x 2.2 a$ (Barth and Wilson, 1995).

\section{Immunohistochemistry}

Embryos were fixed in $4 \%$ paraformaldehyde at room temperature for $3 \mathrm{~h}$, then washed in PBS-Triton (PBS $+0.3 \%$ Triton $\mathrm{X}-100)$. After $1 \mathrm{~h}$ of incubation in blocking solution (PBS-Triton, $4 \% \mathrm{BSA}, 0.02 \%$ $\mathrm{NaN}_{3}$ ) at $4^{\circ} \mathrm{C}$, primary antibodies diluted in blocking solution were added and left over night for incubation at $4^{\circ} \mathrm{C}$. After subsequent washes in PBS-Triton embryos were incubated with appropriate Alexa conjugated secondary antibodies over night at $4^{\circ} \mathrm{C}$. Again, Embryos were washed several times in PBS-Triton and mounted in Mowiol embedding medium for imaging. For a list of the antibodies used in this study, see Supplementary Table 1. All stainings were imaged using a Zeiss Axio Observer.Z1 microscope equipped with a Yokogawa CSU-X1 spinning disc confocal unit using $25 \mathrm{x}$, or $63 \times$ water-immersion lenses. 
354

355

356

357

358

359

360

361

362

363

364

365

366

367

368

369

370

371

372

373

374

375

376

377

378

379

380

381

382

383

384

385

\section{Chemical treatments}

For chemical treatments embryos were dechorionated at 50\% epiboly and transferred to agar-coated $35 \mathrm{~mm}$ dishes containing forskolin (Biomol) at final concentrations between 0.5 and $300 \mu \mathrm{M}$ in $1 \%$ DMSO. Control experiments were performed simultaneously in $1 \%$ DMSO. All embryos were treated until $24 \mathrm{hpf}$.

\section{Microinjection}

mRNA was synthesised using the HiScribe SP6 RNA Synthesis Kit (NEB) and capped using the Vaccinia Capping System (NEB) following the protocols provided by the manufacturer. Embryos were injected at one-cell stage. Injected volumes are indicated in the respective figures.

\section{Light Histology}

Three day old (72 hpf) wild type and gpr161 mutant embryos were fixed in $2.5 \%$ glutaraldehyde in $0.01 \mathrm{M}$ sodium cacodylate buffer for two hours, washed in buffer, dehydrated in an increasing acetone series and embedded in EMBed 812 epoxy resin. After polymerisation for 48 hours at $60^{\circ} \mathrm{C}$, embryos were cut serially with an Autocut 5020 (Reichert, Austria) and a Diatome Butler knife (Diatome, Switzerland). $2 \mu \mathrm{m}$ thick serial sections were stained according to Richardson (Richardson et al., 1960) for 10 minutes, washed, and mounted in cedarwood oil. Images were taken with a Leica DM5000B microscope using a Leica DFC 490 digital camera and Leica application suite v. 4.8 (Leica, Germany).

\section{Electron microscopy}

Embryos were fixed with $2.5 \%$ glutaraldehyde in $0.01 \mathrm{M}$ sodium cacodylate buffer containing $5 \%$ sucrose at $4^{\circ} \mathrm{C}$ for two hours. After washing in cacodylate buffer, specimens were post fixed in reduced osmium ( $2 \%$ osmium tetroxide and $3 \%$ potassium ferrocyanide in $0.1 \mathrm{M}$ cacodylate buffer) for two hours at $4^{\circ} \mathrm{C}$, dehydrated in an ethanol series, critical point dried with an EMS $850 \mathrm{CPD}$ (Electron Microscopy Services, Germany), mounted and $20 \mathrm{~nm}$ gold sputtered with a CCU-010 sputter coater (Safematic, Switzerland), and examined with a DSM950 scanning electron microscope (Zeiss, Germany). Images were taken with a Pentax digital camera and PK_Tether 0.7.0 free software.

\section{Data Presentation and Analysis}

All data presented in this study were analyzed with $\mathrm{R}$ using the RStudio integrated development environment and plotted using the "ggplot2" package (Rstudio Team, 2016; Wickham, 2016).

Statistical significance of differences in expression levels between groups were calculated on at least three biological replicates with the Wilcoxon rank sum test, corrected for multiple comparisons using the Benjamini-Hochberg FDR method. 
Statistical significance of a difference in MP or SSF numbers between groups was determined using one-way ANOVA corrected for unequal variances and the Games-Howell post-hoc test for pairwise comparison as implemented in the "userfriendlyscience" package (Peters, 2017). P values are indicated as follows: * $\mathrm{p}<0.05 ;{ }^{*} \mathrm{p}<0.01 ; \mathrm{p}<0.001$; ns not significant. Sample sizes $(\mathrm{N})$ are given in the respective figure legends.

\section{Acknowledgements}

We are grateful to Dzenana Tufegdzic for fish care, and to Dirk Meyer, Robin Kimmel and Kathi Klee for helpful discussions and/or comments on the manuscript. This work was supported by funding from the Austrian Science Fund (FWF) and the Tyrolean Science Fund (TWF) (FWF P27338 (to P.A.), FWF P30441 (to E.S.), TWF 236277 (to D.R.)).

\section{Competing interests}

The authors declare they have no competing interests.

\section{References}

Ayers KL, Thérond PP. 2010. Evaluating Smoothened as a G-protein-coupled receptor for Hedgehog signalling. Trends Cell Biol 20:287-298. doi:10.1016/j.tcb.2010.02.002

Bachmann VA, Mayrhofer JE, llouz R, Tschaikner P, Raffeiner P, Röck R, Courcelles M, Apelt F, Lu T-W, Baillie GS, Thibault P, Aanstad P, StelzI U, Taylor SS, Stefan E. 2016. Gpr161 anchoring of PKA consolidates GPCR and cAMP signaling. Proc Natl Acad Sci 113:7786-7791. doi:10.1073/pnas.1608061113

Barresi MJ, Stickney HL, Devoto SH. 2000. The zebrafish slow-muscle-omitted gene product is required for Hedgehog signal transduction and the development of slow muscle identity. Development 127:2189-2199.

Barth KA, Wilson SW. 1995. Expression of zebrafish nk2.2 is influenced by sonic hedgehog/vertebrate hedgehog-1 and demarcates a zone of neuronal differentiation in the embryonic forebrain. Development 121:1755-1768.

Briscoe J, Sussel L, Serup P, Hartigan-O'Connor D, Jessell TM, Rubenstein JLR, Ericson J. 1999. Homeobox gene Nkx2.2 and specification of neuronal identity by graded Sonic hedgehog signalling. Nature 398:622-627. doi:10.1038/19315

Briscoe J, Thérond PP. 2013. The mechanisms of Hedgehog signalling and its roles in development and disease. Nat Rev Mol Cell Biol 14:416-429.

Carr AC, Moore SD. 2012. Robust Quantification of Polymerase Chain Reactions Using Global Fitting. 
PLoS One 7:e37640. doi:10.1371/journal.pone.0037640

Chen W, Burgess S, Hopkins N. 2001. Analysis of the zebrafish smoothened mutant reveals conserved and divergent functions of hedgehog activity. Development 128:2385-2396.

Chung W-S, Stainier DYR. 2008. Intra-Endodermal Interactions Are Required for Pancreatic $\beta$ Cell Induction. Dev Cell 14:582-593. doi:10.1016/j.devcel.2008.02.012

Concordet JP, Lewis KE, Moore JW, Goodrich L V, Johnson RL, Scott MP, Ingham PW. 1996. Spatial regulation of a zebrafish patched homologue reflects the roles of sonic hedgehog and protein kinase $\mathrm{A}$ in neural tube and somite patterning. Development 122:2835-46.

Corbit KC, Aanstad P, Singla V, Norman AR, Stainier DYR, Reiter JF. 2005. Vertebrate Smoothened functions at the primary cilium. Nature 437:1018-1021. doi:10.1038/nature04117

Dessaud E, Yang LL, Hill K, Cox B, Ulloa F, Ribeiro A, Mynett A, Novitch BG, Briscoe J. 2007. Interpretation of the sonic hedgehog morphogen gradient by a temporal adaptation mechanism. Nature 450:717-720. doi:10.1038/nature06347

Edgar RC. 2004. MUSCLE: multiple sequence alignment with high accuracy and high throughput. Nucleic Acids Res 32:1792-1797. doi:10.1093/nar/gkh340

García-Nafría J, Watson JF, Greger IH. 2016. IVA cloning: A single-tube universal cloning system exploiting bacterial In Vivo Assembly. Sci Rep 6:27459. doi:10.1038/srep27459

Guner B, Karlstrom RO. 2007. Cloning of zebrafish nkx6.2 and a comprehensive analysis of the conserved transcriptional response to Hedgehog/Gli signaling in the zebrafish neural tube. Gene Expr Patterns 7:596-605. doi:10.1016/j.modgep.2007.01.002

Hammerschmidt M, Bitgood MJ, McMahon AP. 1996. Protein kinase A is a common negative regulator of Hedgehog signaling in the vertebrate embryo. Genes Dev 10:647-658. doi:10.1101/gad.10.6.647

Huang P, Ahkmetova L, Schier AF, Zimmerman S, Pauli A, Thyme SB, Gagnon JA, Montague TG, Richter C, Valen E. 2014. Efficient mutagenesis by Cas9 protein-mediated oligonucleotide insertion and large-scale assessment of single-guide RNAs. PLoS One 9:e98186. doi:10.1371/journal.pone.0098186

Hui C-C, Angers S. 2011. Gli proteins in development and disease. Annu Rev Cell Dev Biol 27:513-537. doi:10.1146/annurev-cellbio-092910-154048

Humke EW, Dorn K V, Milenkovic L, Scott MP, Rohatgi R. 2010. The output of Hedgehog signaling is controlled by the dynamic association between Suppressor of Fused and the Gli proteins. Genes 
Dev 24:670-682. doi:10.1101/gad.1902910

449

450

451

452

453

454

455

456

457

458

459

460

461

462

463

464

465

466

467

468

469

470

471

472

473

474

475

476

477

478

Hwang S-H, White KA, Somatilaka BN, Shelton JM, Richardson JA, Mukhopadhyay S. 2018. The G protein-coupled receptor Gpr161 regulates forelimb formation, limb patterning and skeletal morphogenesis in a primary cilium-dependent manner. Development 145:dev154054. doi:10.1242/dev.154054

Ingham PW, Nakano Y, Seger C. 2011. Mechanisms and functions of Hedgehog signalling across the metazoa. Nat Rev Genet 12:393-406.

Jiang J, Hui C. 2008. Hedgehog Signaling in Development and Cancer. Dev Cell 15:801-812. doi:10.1016/j.devcel.2008.11.010

Kimmel CB, Ballard WW, Kimmel SR, Ullmann B, Schilling TF. 1995. Stages of embryonic development of the zebrafish. Dev Dyn 203:253-310. doi:10.1002/aja.1002030302

Klein RS, Rubin JB, Gibson HD, DeHaan EN, Alvarez-Hernandez X, Segal RA, Luster AD. 2001. SDF-1 alpha induces chemotaxis and enhances Sonic hedgehog-induced proliferation of cerebellar granule cells. Development 128:1971-81.

Koudijs MJ, den Broeder MJ, Groot E, van Eeden FJ. 2008. Genetic analysis of the two zebrafish patched homologues identifies novel roles for the hedgehog signaling pathway. BMC Dev Biol 8:15. doi:10.1186/1471-213X-8-15

Koudijs MJ, den Broeder MJ, Keijser A, Wienholds E, Houwing S, van Rooijen EMHC, Geisler R, van Eeden FJM. 2005. The Zebrafish Mutants dre, uki, and lep Encode Negative Regulators of the Hedgehog Signaling Pathway. PLoS Genet 1:e19. doi:10.1371/journal.pgen.0010019

Krauss S, Concordet J-P, Ingham PW. 1993. A functionally conserved homolog of the Drosophila segment polarity gene hh is expressed in tissues with polarizing activity in zebrafish embryos. Cell 75:1431-1444. doi:10.1016/0092-8674(93)90628-4

Li BI, Matteson PG, Ababon MF, Nato AQ, Lin Y, Nanda V, Matise TC, Millonig JH. 2015. The orphan GPCR, Gpr161, regulates the retinoic acid and canonical Wnt pathways during neurulation. Dev Biol 402:17-31. doi:10.1016/j.ydbio.2015.02.007

Marks SA, Kalderon D. 2011. Regulation of mammalian Gli proteins by Costal 2 and PKA in Drosophila reveals Hedgehog pathway conservation. Development 138:2533-2542. doi:10.1242/dev.063479

Montague TG, Cruz JM, Gagnon JA, Church GM, Valen E. 2014. CHOPCHOP: a CRISPR/Cas9 and TALEN web tool for genome editing. Nucleic Acids Res 42:W401-W407. doi:10.1093/nar/gku410 
Mukhopadhyay S, Wen X, Ratti N, Loktev A, Rangell L, Scales SJ, Jackson PK. 2013. The ciliary Gprotein-coupled receptor Gpr161 negatively regulates the Sonic hedgehog pathway via cAMP signaling. Cell 152:210-223. doi:10.1016/j.cell.2012.12.026

Niewiadomski P, Kong JH, Ahrends R, Ma Y, Humke EW, Khan S, Teruel MN, Novitch BG, Rohatgi R. 2014. Gli Protein Activity Is Controlled by Multisite Phosphorylation in Vertebrate Hedgehog Signaling. Cell Rep 6:168-181. doi:10.1016/j.celrep.2013.12.003

Niewiadomski P, Niedziółka SM, Markiewicz Ł, Uśpieński T, Baran B, Chojnowska K. 2019. Gli Proteins: Regulation in Development and Cancer. Cells 8:147. doi:10.3390/cells8020147

Nørholm MH. 2010. A mutant Pfu DNA polymerase designed for advanced uracil-excision DNA engineering. BMC Biotechnol 10:21. doi:10.1186/1472-6750-10-21

Ogden SK, Fei DL, Schilling NS, Ahmed YF, Hwa J, Robbins DJ. 2008. G protein Gai functions immediately downstream of Smoothened in Hedgehog signalling. Nature 456:967-970. doi:10.1038/nature07459

Pal K, Hwang S, Somatilaka B, Badgandi H, Jackson PK, DeFea K, Mukhopadhyay S. 2016. Smoothened determines $\beta$-arrestin-mediated removal of the $G$ protein-coupled receptor Gpr161 from the primary cilium. J Cell Bio/ 212:861-875. doi:10.1083/jcb.201506132

Pan Y, Wang C, Wang B. 2009. Phosphorylation of Gli2 by protein kinase A is required for Gli2 processing and degradation and the Sonic Hedgehog-regulated mouse development. Dev Biol 326:177-189. doi:10.1016/j.ydbio.2008.11.009

Park H-C, Mehta A, Richardson JS, Appel B. 2002. olig2 Is Required for Zebrafish Primary Motor Neuron and Oligodendrocyte Development. Dev Biol 248:356-368. doi:10.1006/DBIO.2002.0738

Peters G-JY. 2017. userfriendlyscience: Quantitative analysis made accessible. R Packag version 06-1. doi:10.17605/OSF.IO/TXEQU

Pusapati G V., Kong JH, Patel BB, Gouti M, Sagner A, Sircar R, Luchetti G, Ingham PW, Briscoe J, Rohatgi R. 2018. G protein-coupled receptors control the sensitivity of cells to the morphogen Sonic Hedgehog. Sci Signal 11:1-16. doi:10.1126/scisignal.aao5749

Raleigh DR, Reiter JF. 2019. Misactivation of Hedgehog signaling causes inherited and sporadic cancers. J Clin Invest. doi:10.1172/JCI120850

Regard JB, Malhotra D, Gvozdenovic-Jeremic J, Josey M, Chen M, Weinstein LS, Lu J, Shore EM, Kaplan FS, Yang Y. 2013. Activation of Hedgehog signaling by loss of GNAS causes heterotopic 
ossification. Nat Med 19:1505-12. doi:10.1038/nm.3314

511

512

513

Richardson KC, Jarett L, Finke EH. 1960. Embedding in epoxy resins for ultrathin sectioning in electron microscopy. Biotech Histochem 35:313-323. doi:10.3109/10520296009114754

Riobo NA, Saucy B, DiLizio C, Manning DR. 2006. Activation of heterotrimeric G proteins by Smoothened. Proc Natl Acad Sci 103:12607-12612. doi:10.1073/pnas.0600880103

Ritz C, Spiess A-N. 2008. qpcR: an R package for sigmoidal model selection in quantitative real-time polymerase chain reaction analysis. Bioinformatics

24:1549-1551. doi:10.1093/bioinformatics/btn227

Rödiger S, Burdukiewicz M, Spiess A-N, Blagodatskikh K. 2017. Enabling reproducible real-time quantitative PCR research: the RDML package. Bioinformatics 33:4012-4014. doi:10.1093/bioinformatics/btx528

Rstudio Team. 2016. RStudio: Integrated development for R. RStudio, Inc., Boston MA. RStudio.

Schmitt EA, Dowling JE. 1999. Early retinal development in the zebrafish, Danio rerio: Light and electron microscopic analyses. J Comp Neurol 404:515-536. doi:10.1002/(SICI)10969861(19990222)404:4<515::AID-CNE8>3.0.CO;2-A

Shimada IS, Hwang S-HH, Somatilaka BN, Wang X, Skowron P, Kim J, Kim M, Shelton JM, Rajaram V, Xuan Z, Taylor MD, Mukhopadhyay S. 2018. Basal Suppression of the Sonic Hedgehog Pathway by the G-Protein-Coupled Receptor Gpr161 Restricts Medulloblastoma Pathogenesis. Cell Rep 22:1169-1184. doi:10.1016/j.celrep.2018.01.018

Singh J, Wen X, Scales SJ. 2015. The orphan G protein-coupled receptor Gpr175 (Tpra40) enhances Hedgehog signaling by modulating cAMP levels. J Biol Chem. doi:10.1074/jbc.M115.665810

Stückemann T, Wegleiter T, Stefan E, Nägele O, Tarbashevich K, Böck G, Raz E, Aanstad P. 2012. Zebrafish Cxcr4a determines the proliferative response to Hedgehog signalling. Development 139:2711-2720.

Torres-Quesada O, Mayrhofer JE, Stefan E. 2017. The many faces of compartmentalized PKA signalosomes. Cell Signal 37:1-11. doi:10.1016/j.cellsig.2017.05.012

Tuson M, He MM, Anderson K V. 2011. Protein kinase A acts at the basal body of the primary cilium to prevent Gli2 activation and ventralization of the mouse neural tube. Development 138:49214930. doi:10.1242/dev.070805

Wang B, Fallon JF, Beachy PA. 2000. Hedgehog-Regulated Processing of Gli3 Produces an Anterior/Posterior Repressor Gradient in the Developing Vertebrate Limb. Cell 100:423-434. 
doi:10.1016/S0092-8674(00)80678-9

542

Whitfield TT, Granato $M$, van Eeden FJ, Schach U, Brand $M$, Furutani-Seiki $M$, Haffter $P$, Hammerschmidt M, Heisenberg CP, Jiang YJ, Kane DA, Kelsh RN, Mullins MC, Odenthal J, Nüsslein-Volhard C. 1996. Mutations affecting development of the zebrafish inner ear and lateral line. Development 123:241-54. doi:10.1016/S1350-9462(98)00010-X

Wickham H. 2016. ggplot2: Elegant Graphics for Data Analysis, Use R! Springer-Verlag New York. doi:10.1007/978-3-319-24277-4

Wolff C, Roy S, Ingham PW. 2003. Multiple muscle cell identities induced by distinct levels and timing of Hedgehog activity in the zebrafish embryo. Curr Biol 13:1169-1181. doi:10.1016/S09609822(03)00461-5

551

Zhao Z, Lee RTH, Pusapati G V, Iyu A, Rohatgi R, Ingham PW. 2016. An essential role for Grk2 in 
bioRxiv preprint doi: https://doi org/10.1101/616482; this version posted April 23 2019. The copyright holder for this preprint (which was not certified by peer review) is the author/funder, who has granted bioRxiv a license to display the preprint in perpetuity. It is made available under aCC-BY 4.0 International license.

A

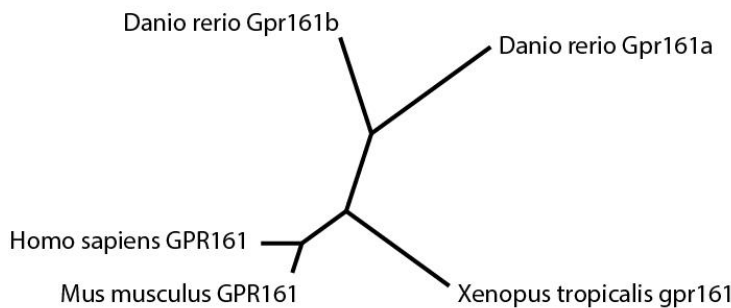

B

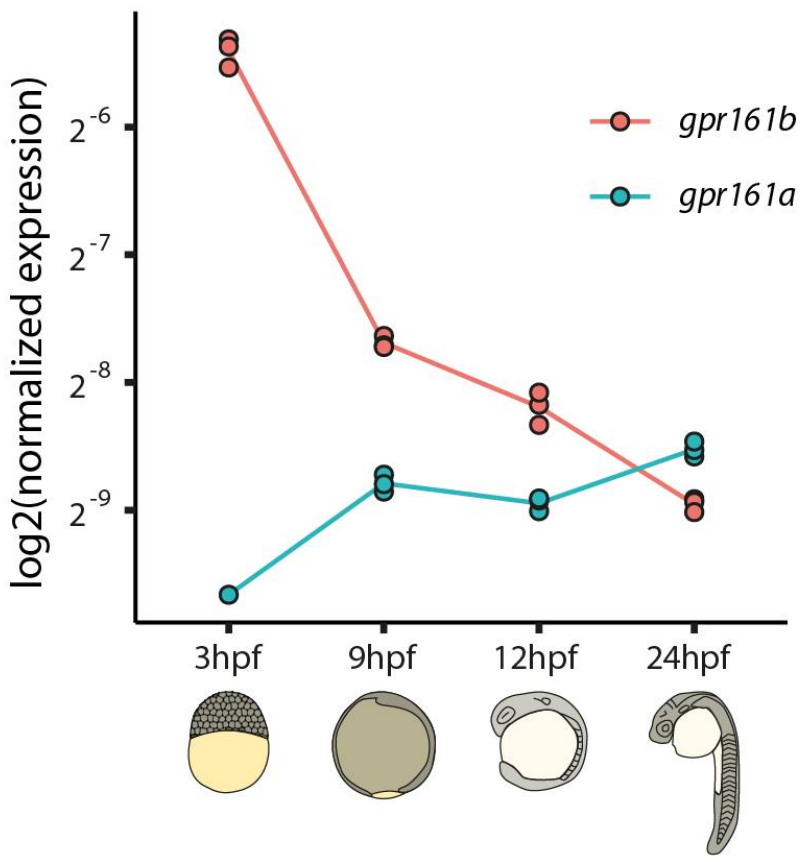

C

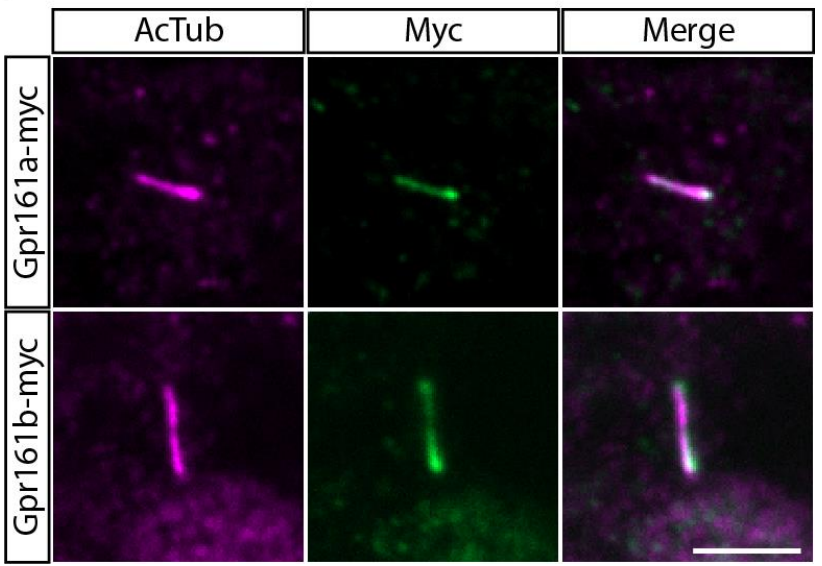

Figure 1. Gpr161 is a conserved ciliary GPCR. (A) Un-rooted cladogram showing the relation between Gpr161 protein sequences of selected organisms. (B) gpr161a and gpr161b transcript levels at different stages of development analysed in whole embryo lysates in triplicates using RT-qPCR. (C) Wildtype embryos were injected with gpr161a-myc or gpr161b-myc mRNA at one-cell stage and fixed at $9 \mathrm{hpf}$ before immunostaining for acetylated tubulin (AcTub; purple), a marker for the ciliary axoneme and Myc (green) (scale bar: $5 \mu \mathrm{m})$. 
bioRxiv preprint doi: https://doi.org/10.1101/616482; this version posted April 23,2019 . The copyright holder for this preprint (which was not certified by peer review) is the author/funder, who has granted bioRxiv a license to display the preprint in perpetuity. It is made available under aCC-BY 4.0 International license.

A

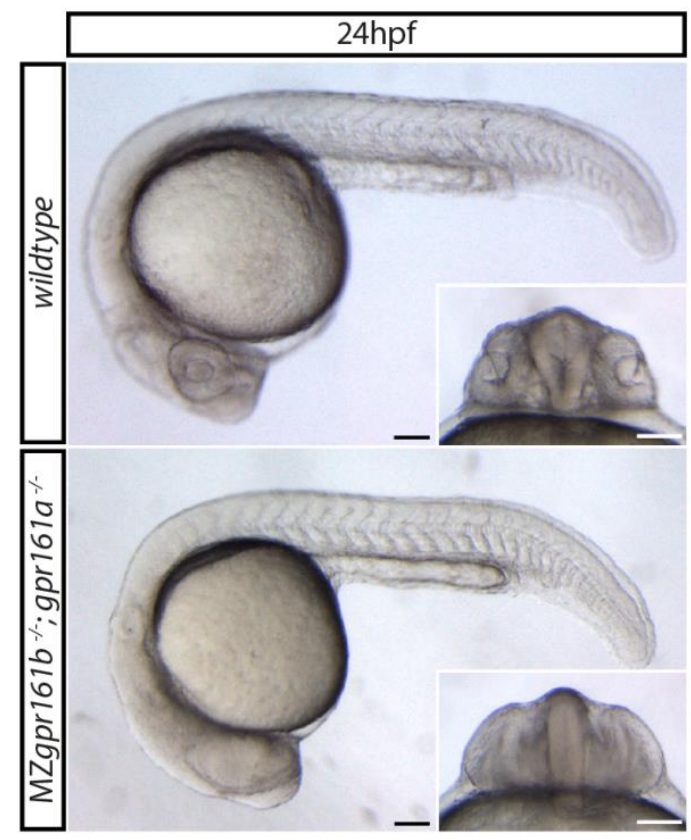

C

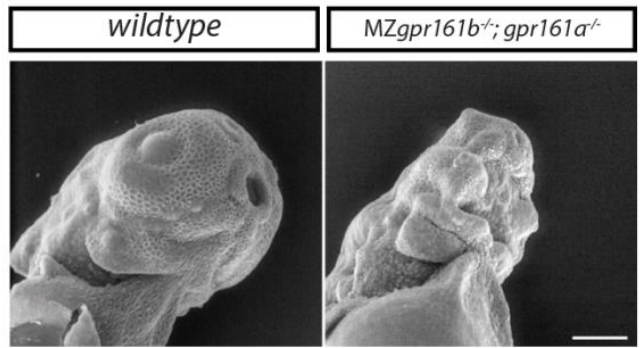

B

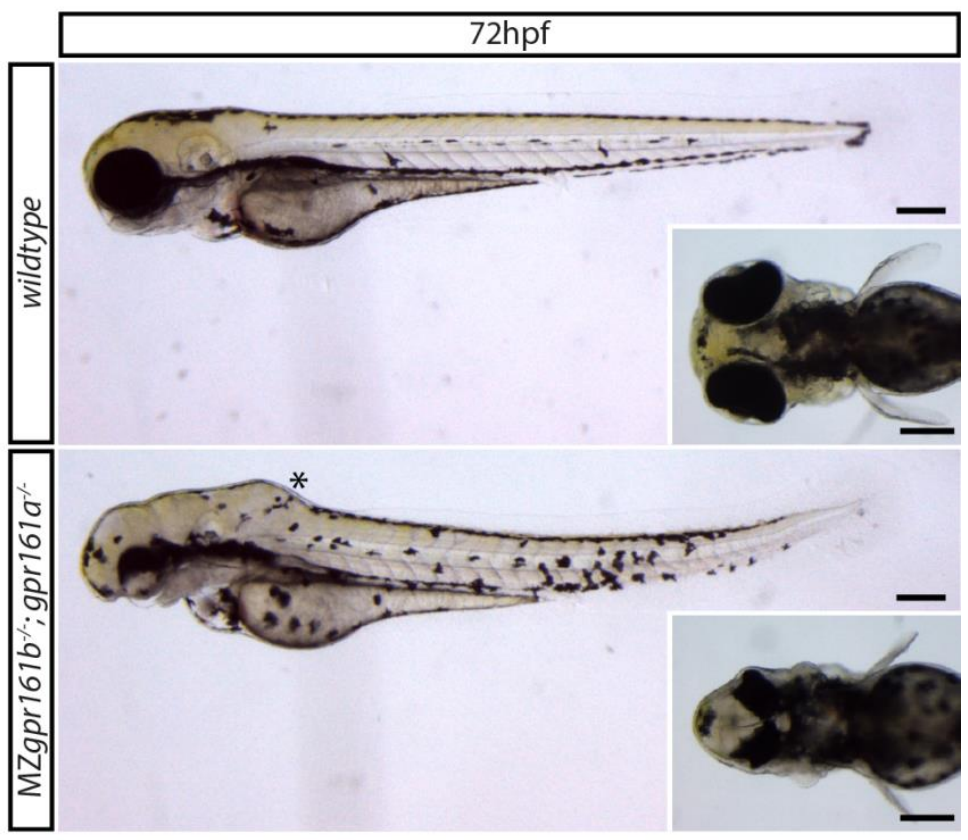

D

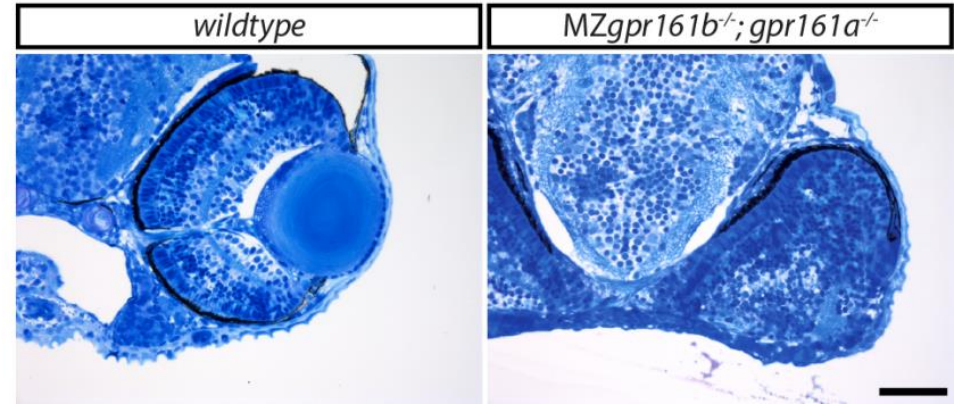

Figure 2. Gpr161 is essential during embryonic development. (A) Lateral view of wildtype and MZgpr161 $b^{-/} ;$gpr161a embryos at $24 \mathrm{hpf}$ (scale bars: $100 \mu \mathrm{m}$ ); Insets: ventral view of the developing eyes. (B) Wildtype and MZgpr161b\%; gpr161a $\%$ embryos at $72 \mathrm{hpf}$; Asterisk indicates swollen hindbrain (scale bars: 200 $\mu \mathrm{m}$ ); Insets: dorsal view of the head (C) Ventrolateral-view of the craniofacial region of wildtype and MZgpr161 $\mathrm{b}^{-/} ;$gpr161a ${ }^{-/}$embryos at $72 \mathrm{hpf}$ taken by scanning electron microscopy (scale bar: $100 \mu \mathrm{m}$ ). (D) Transverse semi-thin sections of the eye in wildtype and MZgpr161 $\mathrm{b}^{-1}$; gpr161 $\%$ embryos fixed at $72 \mathrm{hpf}$ (Richardson staining, scale bars: $50 \mu \mathrm{m}$ ). 
A

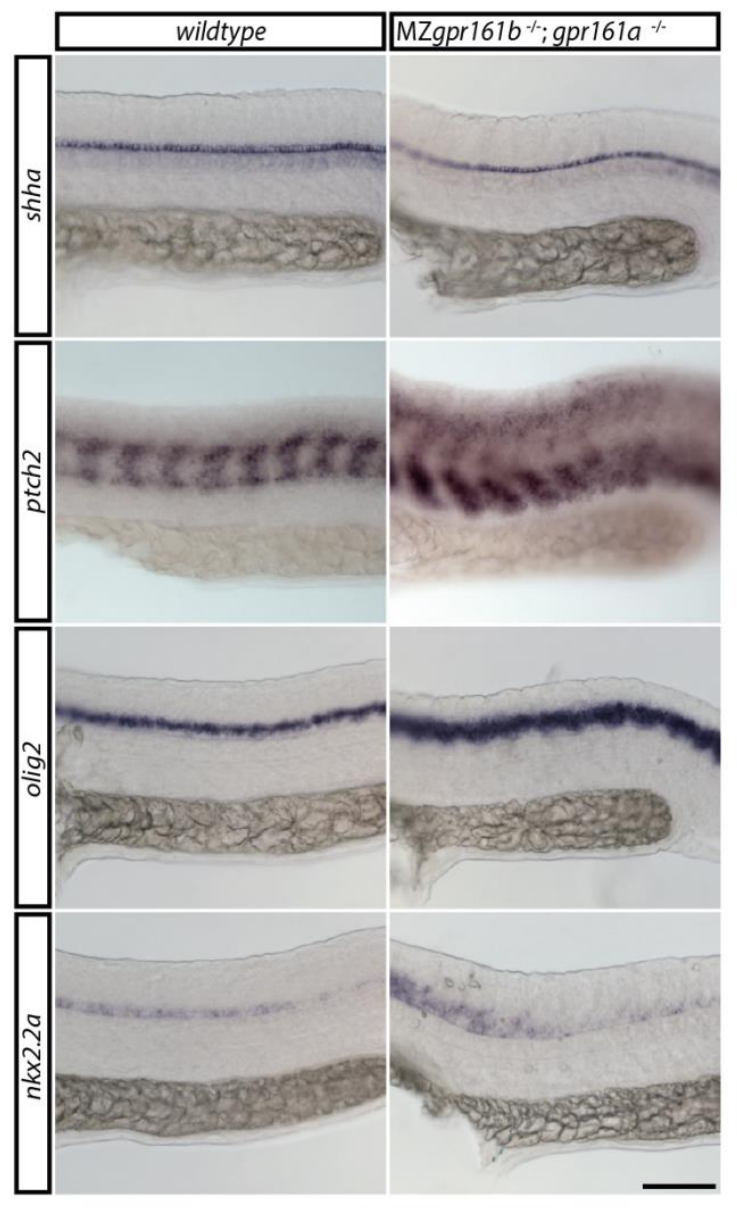

D

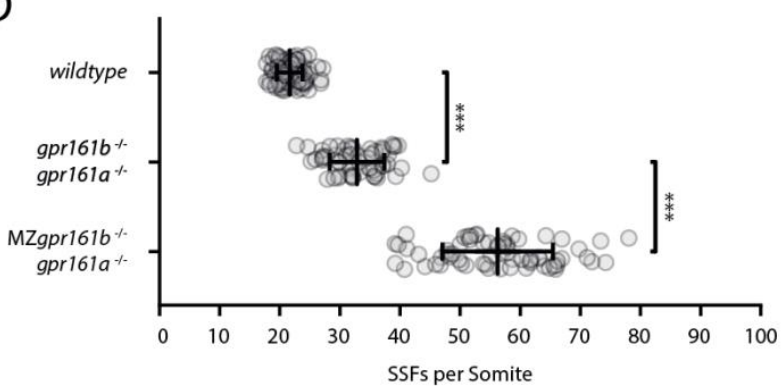

B

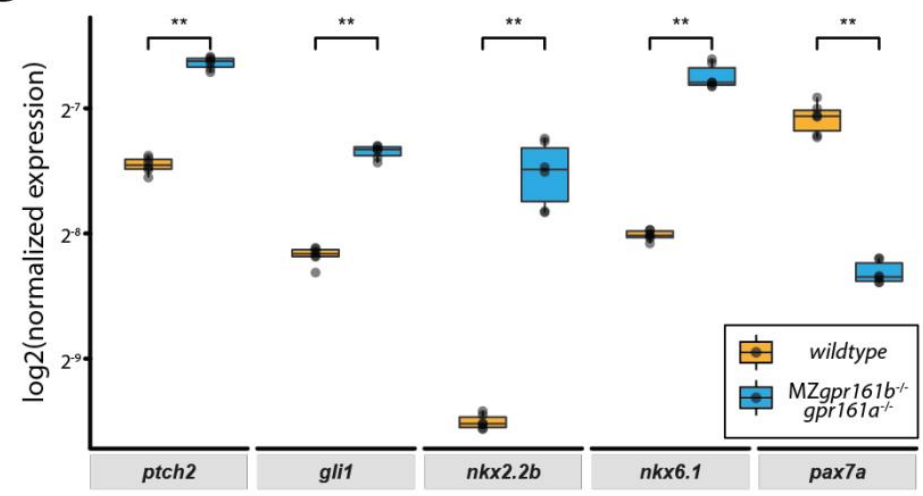

C

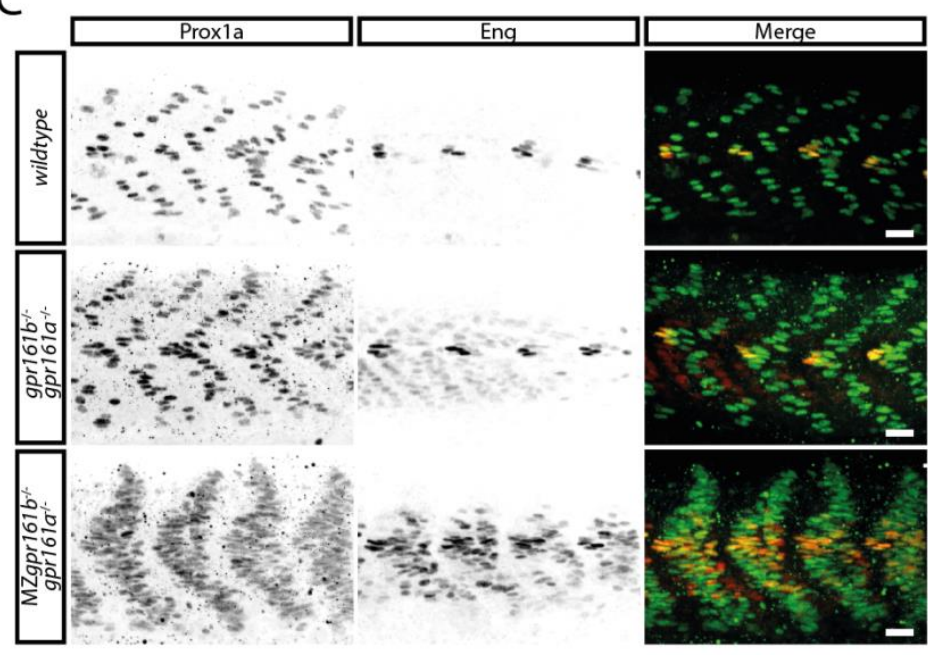

$\mathrm{E}$

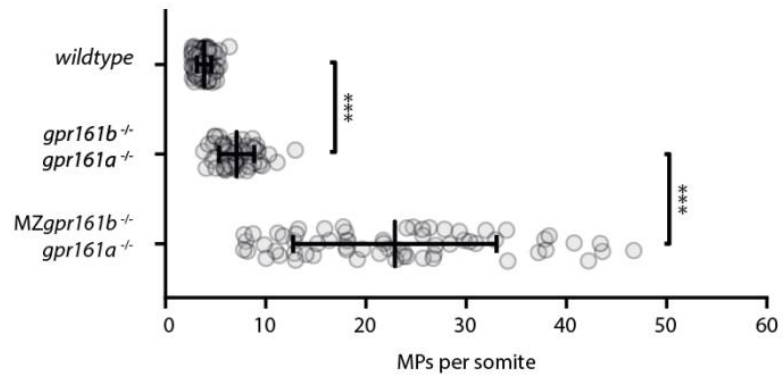

Figure 3. Hh signalling activity is increased in gpr161 mutants. (A) RNA in situ hybridization of shh, ptch2, olig2 and $n k x 2.2 a$ transcripts in wildtype and MZgpr161b\%;gpr161a \% embryos fixed at $24 \mathrm{hpf}$ (lateral view, scale bar: 100 $\mu \mathrm{m})$. (B) Transcript levels of ptch2, gli1, nkx2.2b, nkx6.1 and pax7a in wildtype and MZgpr161b\%;gpr161a \% embryos at 24hpf determined by RT-qPCR ( $n=3)$ (C) Immunostaining of Prox1 and Eng proteins in $24 \mathrm{hpf}$ zebrafish embryos reveal the number of MPs (Prox1a/Eng double positive) as well as SFFs (Prox1 positive) in wild-type, gpr161b\%; gpr161a \% and MZgpr161b \%; gpr161\% embryos fixed at $24 \mathrm{hpf}$ (scale bar: $20 \mu \mathrm{m}$ ). Number of (D) SSFs and (E) MPs per somite in wild-type ( $\mathrm{n}=93$ somites in 22 embryos), gpr161b\% $\%$ gpr161a $\%$ (n=60 somites in 20 embryos) and MZgpr161b \% gpr161a \% ( $\mathrm{n}=66$ somites in 22 embryos) embryos fixed at $24 \mathrm{hpf}$. 

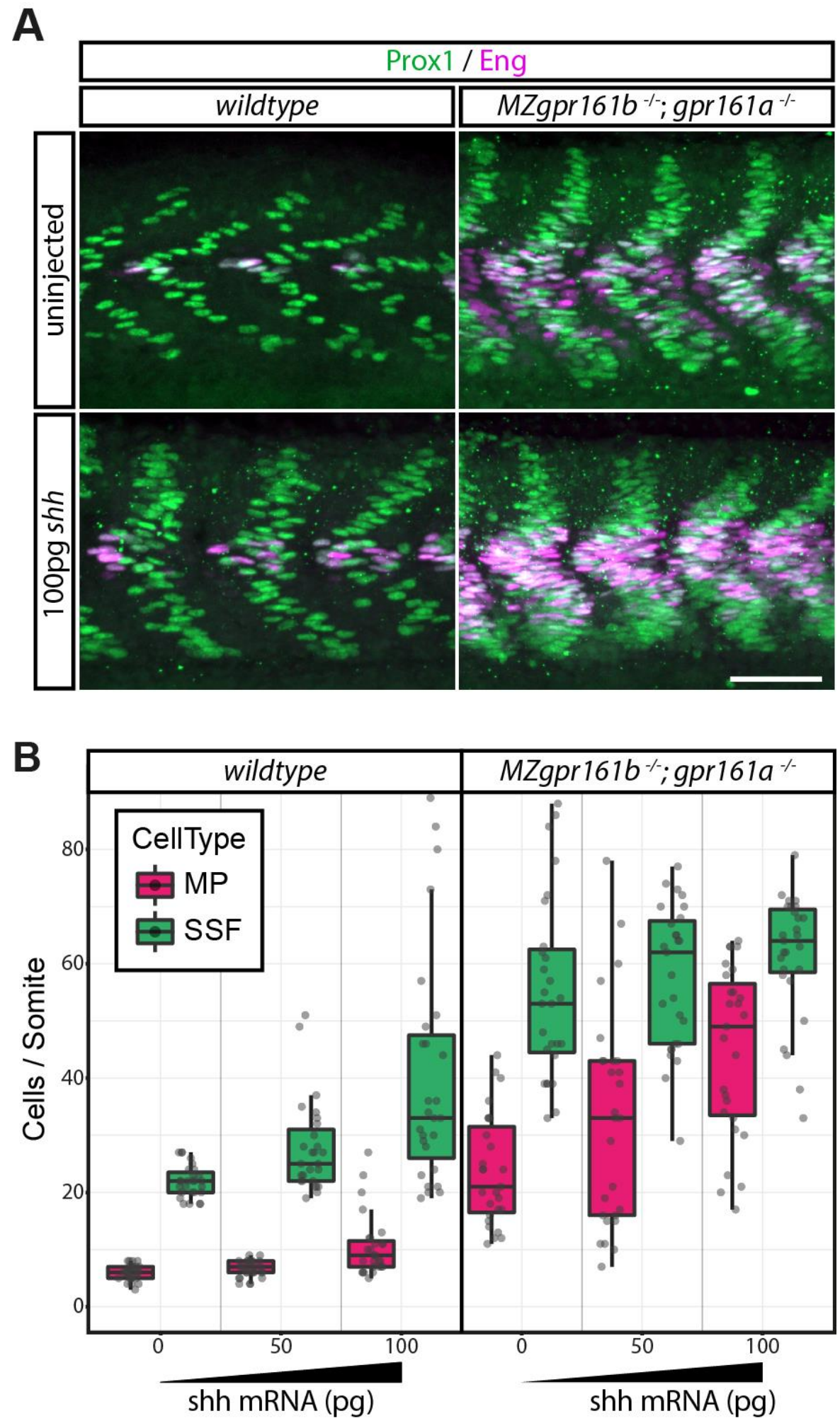

Figure 4. Injection of shh mRNA can elevate hh signalling outcomes in gpr161 mutants. (A) Prox1 (green)/ Eng (purple)

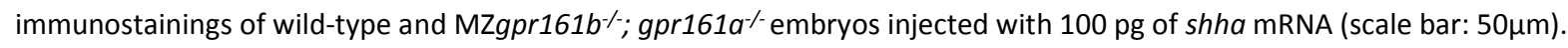

(B) Quantification of MPs and SSFs in wild-type and MZgpr161 $b^{\%}$; gpr161a $\%$ embryos injected with increasing amounts of 
bioRxiv preprint doi: https://doi.org/10.1101/616482; this version posted April 23, 2019. The copyright holder for this preprint (which was not certified by peer review) is the author/funder, who has granted bioRxiv a license to display the preprint in perpetuity. It is made available under aCC-BY 4.0 International license.

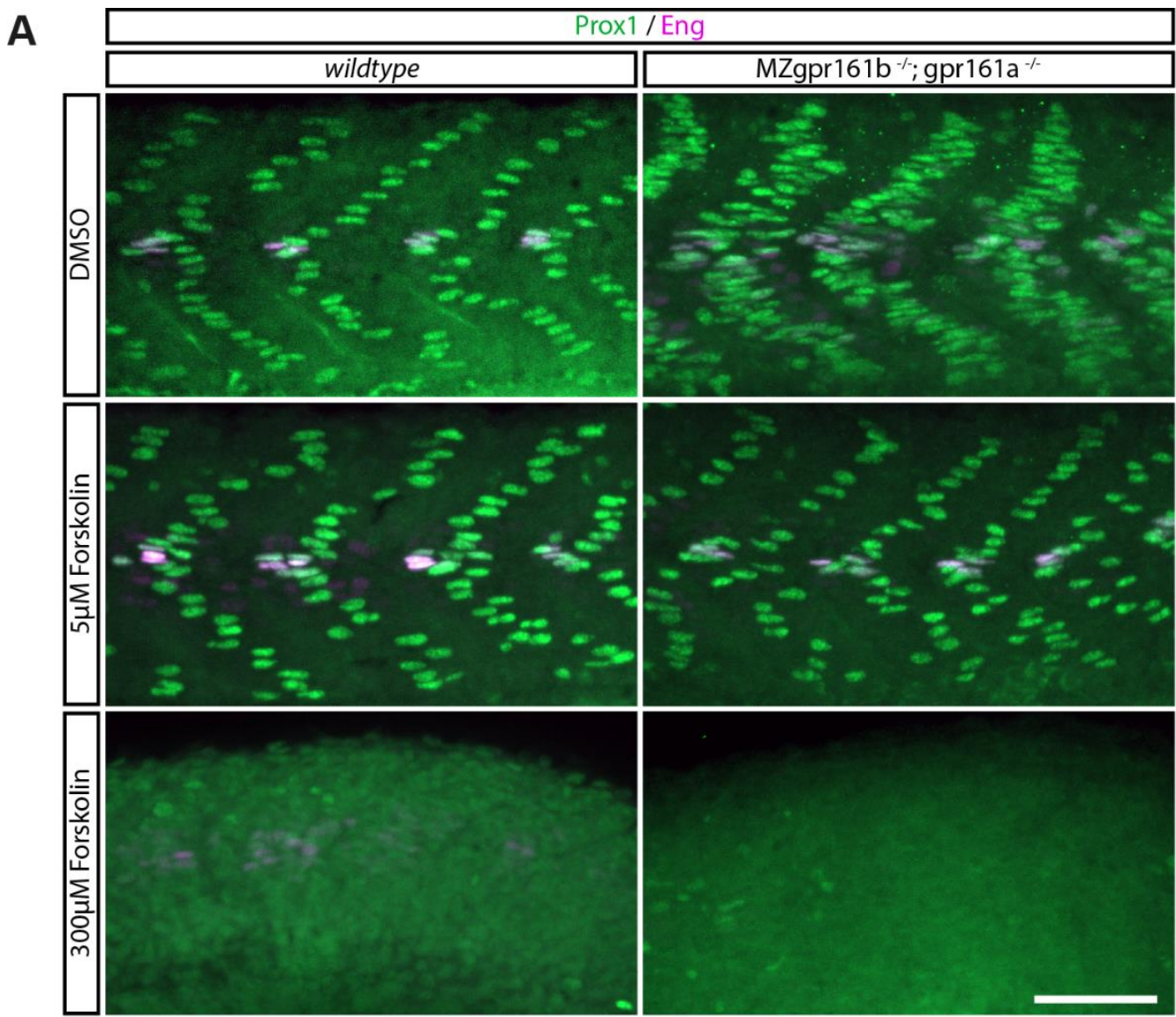

B

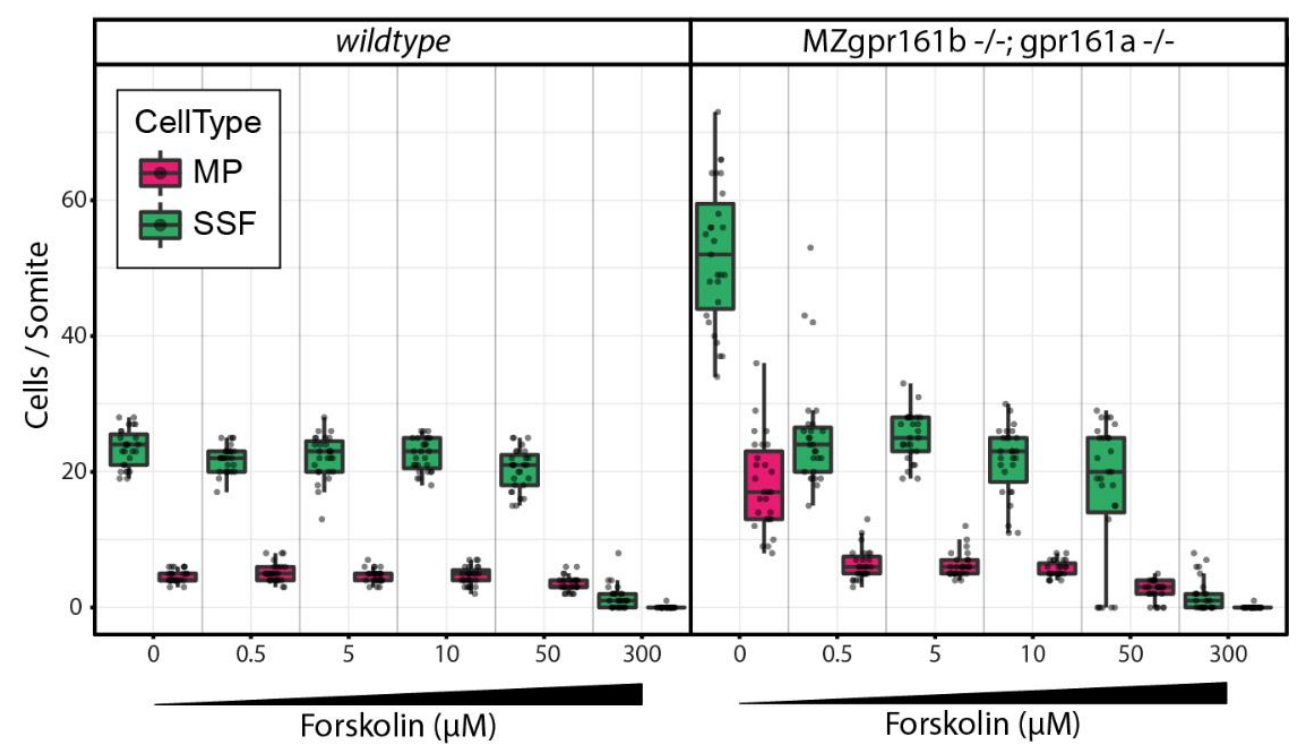

Figure 5. Forskolin treatments can rescue the gpr161 phenotype. (A) Prox1 (green)/ Eng (purple) immunostainings of wild-

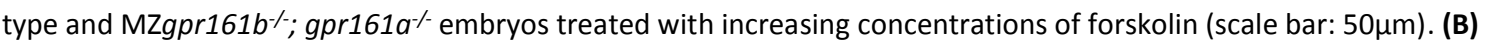

587 Quantification of MPs and SSFs in wild-type and MZgpr161 $b^{-/}$; gpr161a $\%$ embryos treated with increasing concentrations of forskolin (for each experiment, $\mathrm{n}=27$ somites in 9 embryos). 
bioRxiv preprint doi: https://doi org/10.1101/616482; this version posted April 23,2019 . The copyright holder for this preprint (which was not certified by peer review) is the author/funder, who has granted bioRxiv a license to display the preprint in perpetuity. It is made available under aCC-BY 4.0 International license.

A

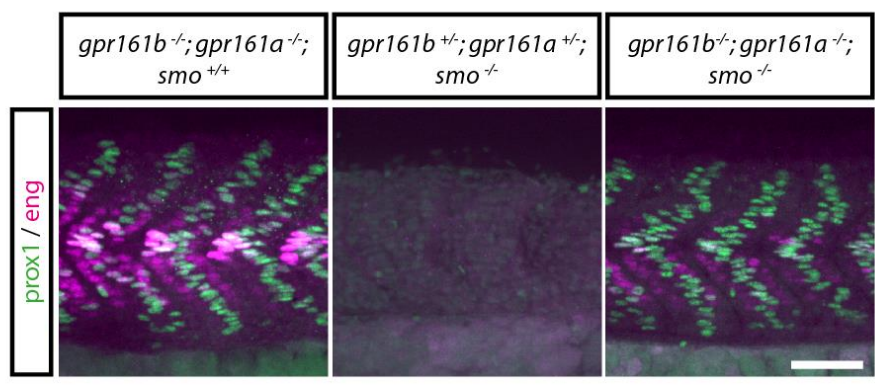

B

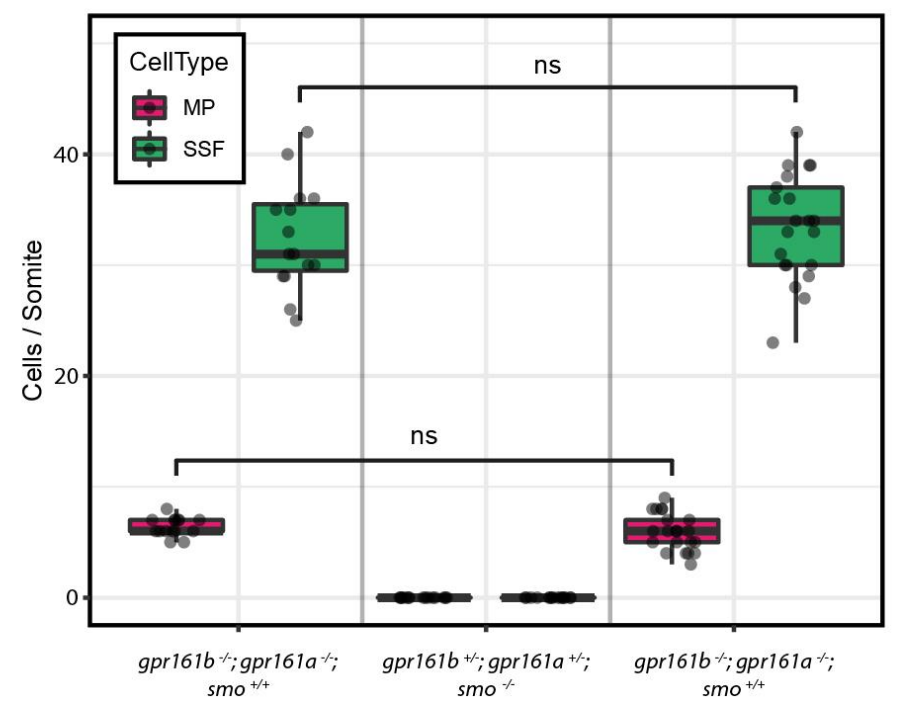

C

\begin{tabular}{|c|c|}
\hline $\begin{array}{c}\text { gpr161b } ; \text {; } g \text { pr161a } \\
\text { smo }^{+/+}\end{array}$ & 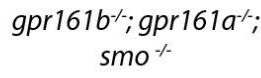 \\
\hline
\end{tabular}

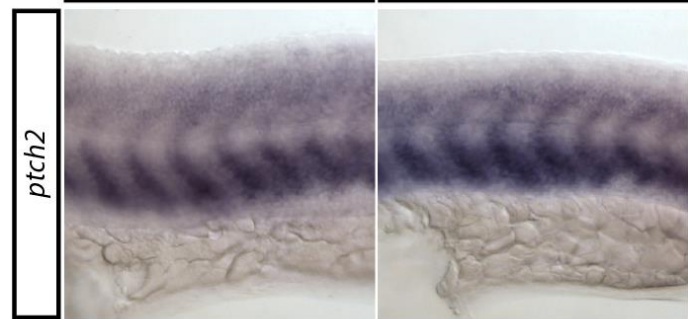

$\frac{2}{2}$

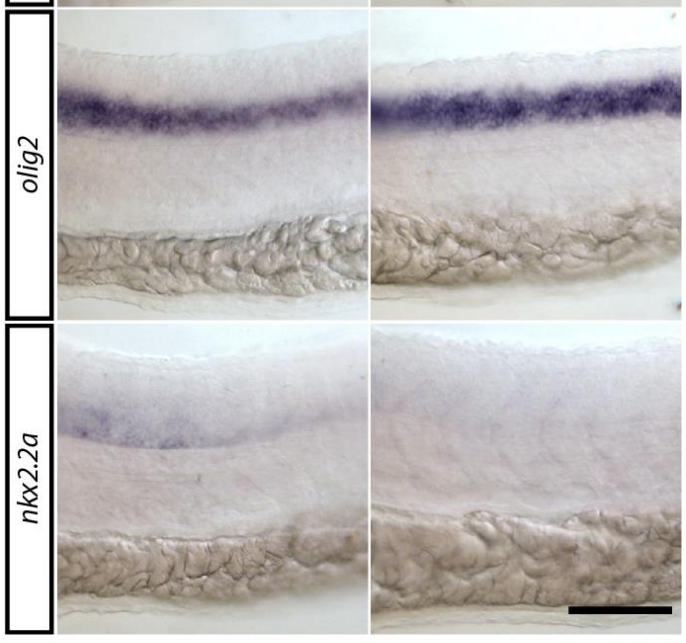

Figure 6. The requirement for Smo during high-level Hh signalling in gpr161 mutants is tissue-specific. (A) Prox1 (green)/

Eng (purple) immunostainings of wildtype and MZgpr161 b//; gpr161a $/$ embryos at $24 \mathrm{hpf}$ after DMSO or $200 \mu \mathrm{M}$

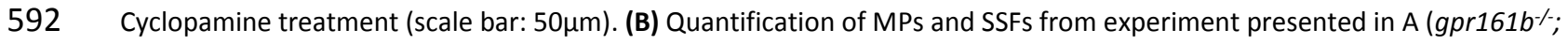

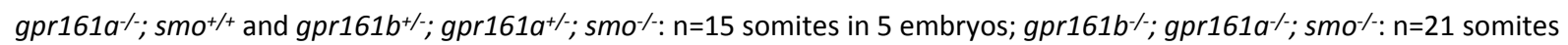
in 7 embryos; all others: $\mathrm{n}=27$ somites in 9 embryos). (C) RNA in situ hybridization of $p t c h 2$, olig 2 and $n k x 2.2 a$ transcripts in

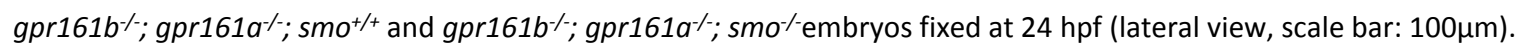


bioRxiv preprint doi: https://doi.org/10.1101/616482; this version posted April 23, 2019. The copyright holder for this preprint (which was not certified by peer review) is the author/funder, who has granted bioRxiv a license to display the preprint in perpetuity. It is made available under aCC-BY 4.0 International license.

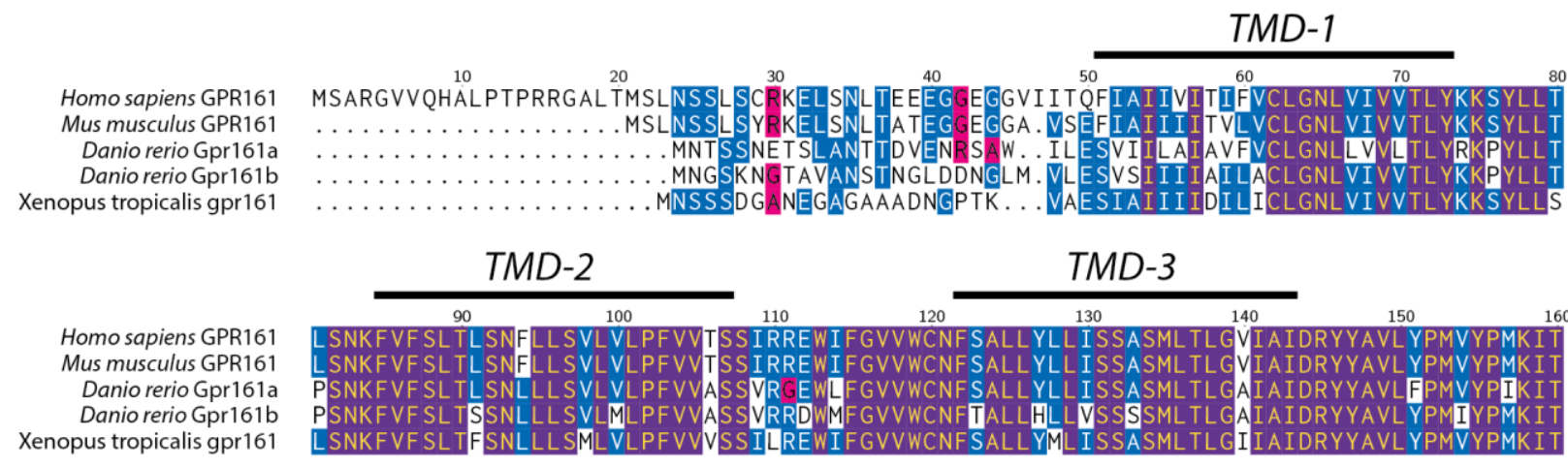

Homo sapiens GPR161
Mus musculus GPR161
Danio rerio Gpr161a
Danio rerio Gpr161b
Xenopus tropicalis gpr161

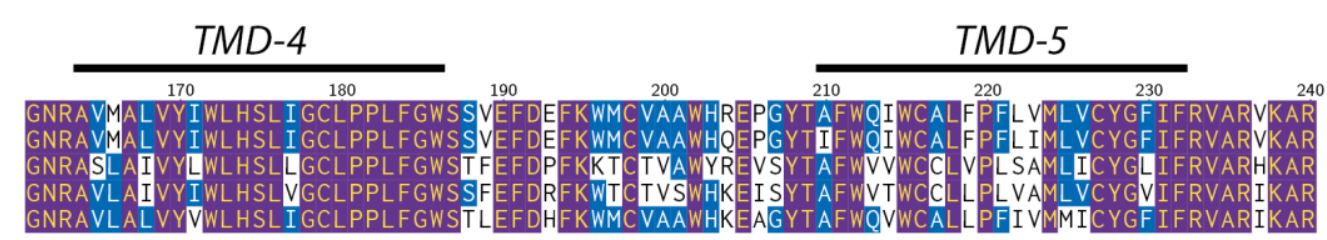

Homo sapiens GPR161
Mus musculus GPR161
Danio rerio Gpr161a
Danio rerio Gpr161b Xenopus tropicalis gpr161

\begin{abstract}
Homo sapiens GPR161
Mus musculus GPR161

Danio rerio Gpr161a

Danio rerio Gpr161b

Xenopus tropicalis gpr161
\end{abstract}
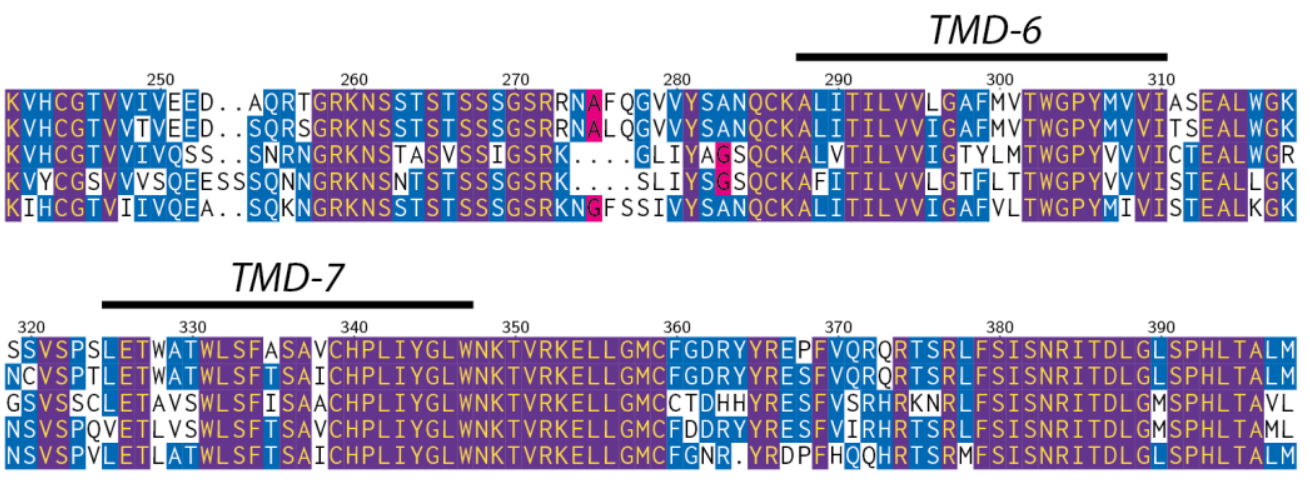

Homo sapiens GPR161
Mus musculus GPR161
Danio rerio Gpr161a
Danio rerio Gpr161b Xenopus tropicalis gpr161

Homo sapiens GPR16 Mus musculus GPR16 Danio rerio Gpr161

Danio rerio Gpr161 Xenopus tropicalis gpr 161

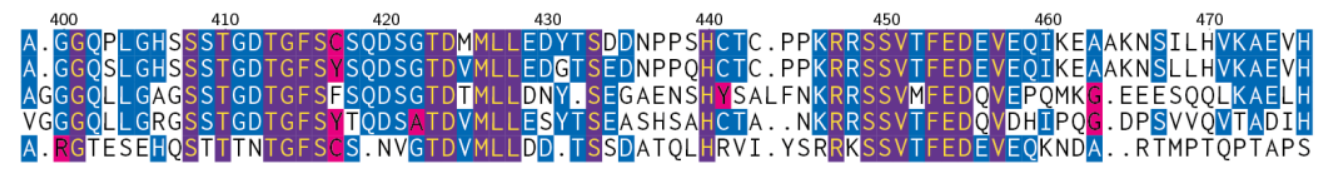

\footnotetext{
Homo sapiens GPR161

Mus musculus GPR16

Danio rerio Gpr161

Danio rerio Gpr161b

Xenopus tropicalis gpr 161
}

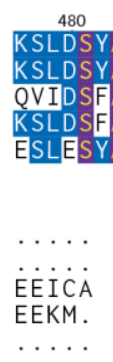

\section{0}

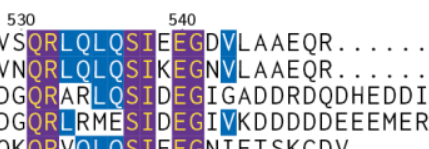

\non conserved

ximilar

$X \geq 50 \%$ conserved

X all match

597 Figure 1-Supplement 1. Multiple Sequence Alignment. The sequences of the Homo sapiens, Mus musculus, Danio rerio and

598 Xenopus tropicalis Gpr161 proteins were aligned using MUSCLE (Edgar, 2004). Transmembrane domains (TMDs) and

599 conserved residues are indicated. 
bioRxiv preprint doi: https://doi org/101101/616482; this version posted April 23,2019 . The copyright holder for this preprint (which was not certified by peer review) is the author/funder, who has granted bioRxiv a license to display the preprint in perpetuity. It is made available under aCC-BY 4.0 International license.

A

gpr161a (ENSDART00000151311.2)

\section{$9.46 \mathrm{~kb}$}

Forward strand

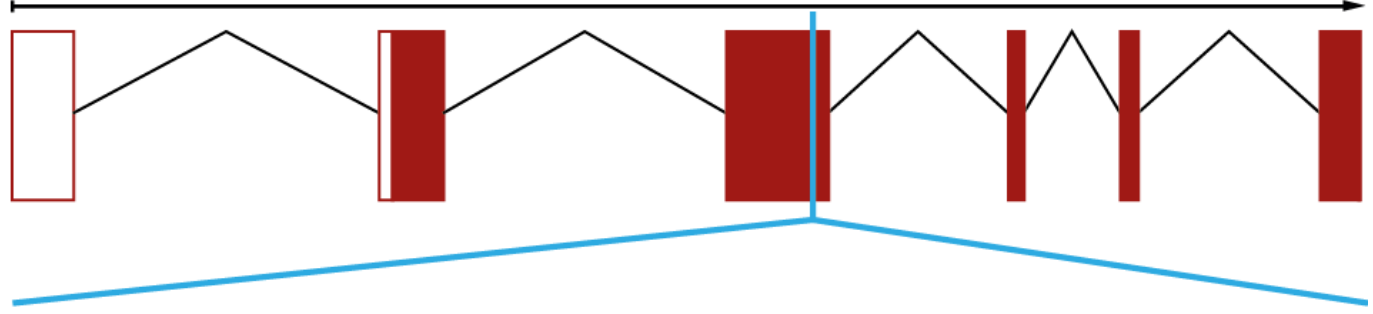

Wt

CCTTATGGGGGAGAGGAAGTGTGTCATCCTGTTTGGAGACCGCGGT------GTCCTGGCTGTCCTTCATCAGTGCG

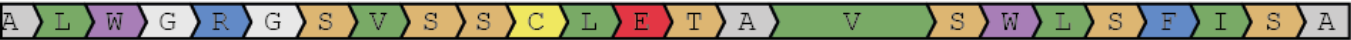

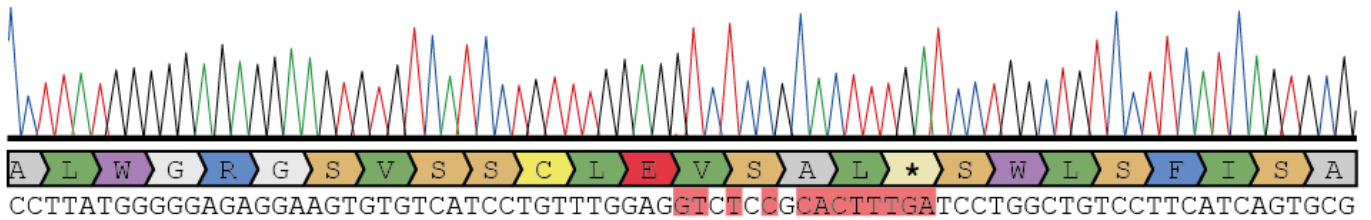

B

gpr161b (ENSDART00000078051.6)

$13.66 \mathrm{~kb}$

Forward strand

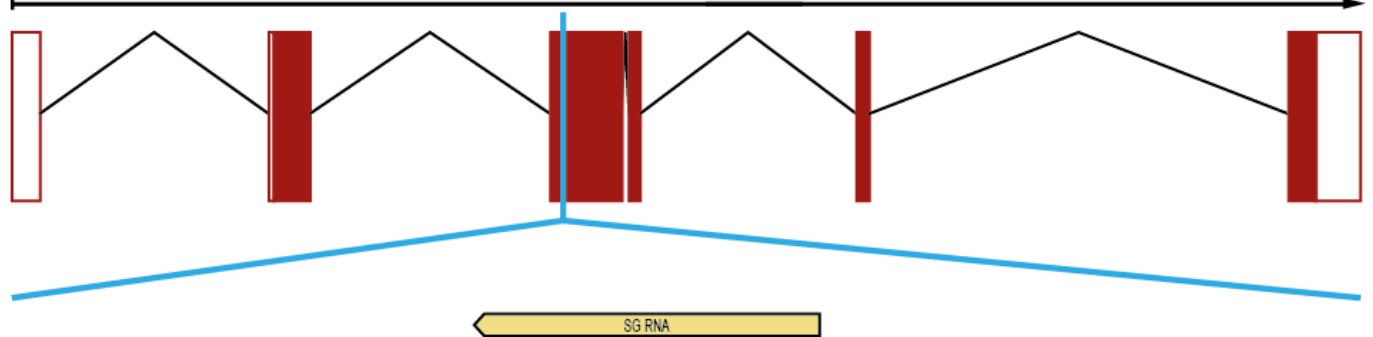

GCAGTATTATACCCCATGATCTACCCCATGAAAATCACCGGAAATCGAGCTGTGCTTGCAATCGTTTACATCTGGCT

wt

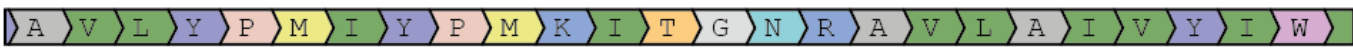

gpr161b $\mathrm{b}^{\mathrm{m} 201}$

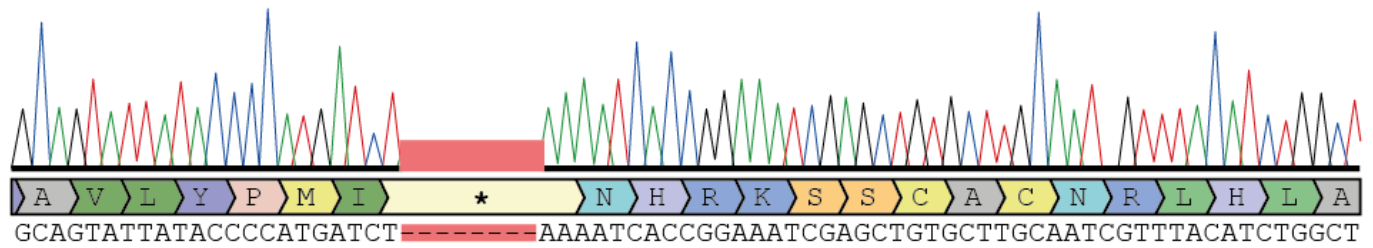

601 Figure 1-Supplement 2. CRISPR knock out strategy. Schematic representation of the gene structure of gpr161a (A) and gpr161b (B) indicating the position of CRISPR sgRNA recognition site and a sequence alignment of the obtained mutant alleles. 
bioRxiv preprint doi: https://doi.org/10.1101/616482; this version posted April 23, 2019. The copyright holder for this preprint (which was not certified by peer review) is the author/funder, who has granted bioRxiv a license to display the preprint in perpetuity. It is made available under aCC-BY 4.0 International license.

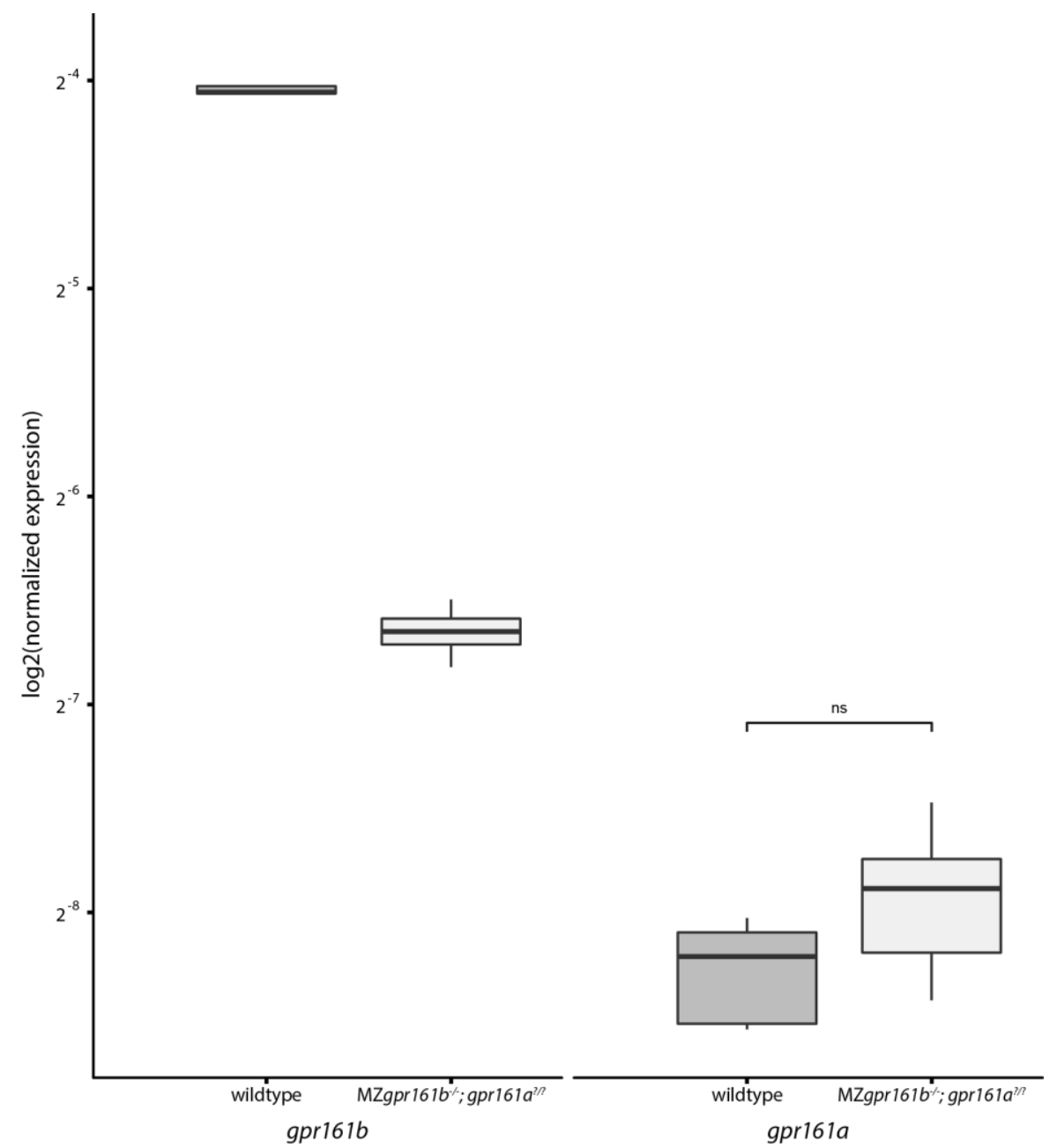

606 Figure 2-Supplement 1. Maternal loss of gpr161b does not lead to genetic compensation by gpr161a. Transcript levels of 607 gpr161a and gpr161b in single embryos at 2-cell stage as determined by qPCR ( $\mathrm{n}=6)$ 
bioRxiv preprint doi: https://doi.org/10.1101/616482; this version posted April 23, 2019. The copyright holder for this preprint (which was not certified by peer review) is the author/funder, who has granted bioRxiv a license to display the preprint in perpetuity. It is made available under aCC-BY 4.0 International license.

A

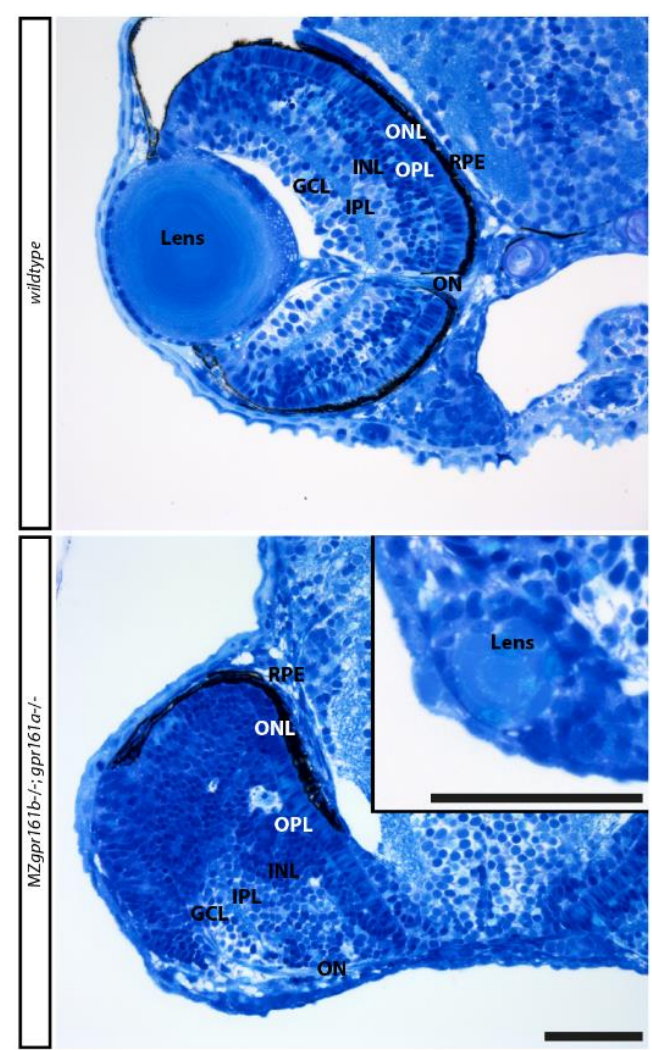

B

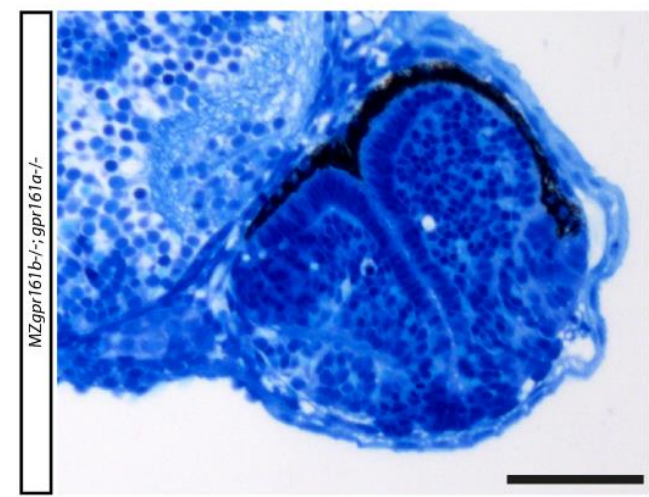

C

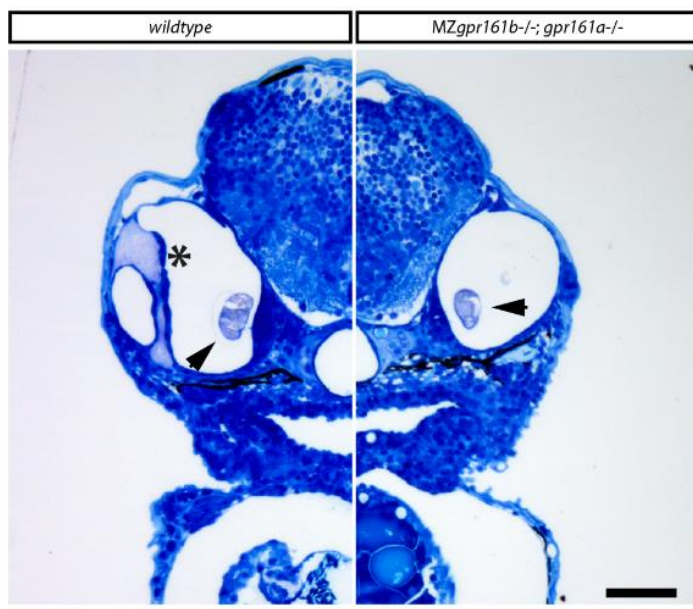

D

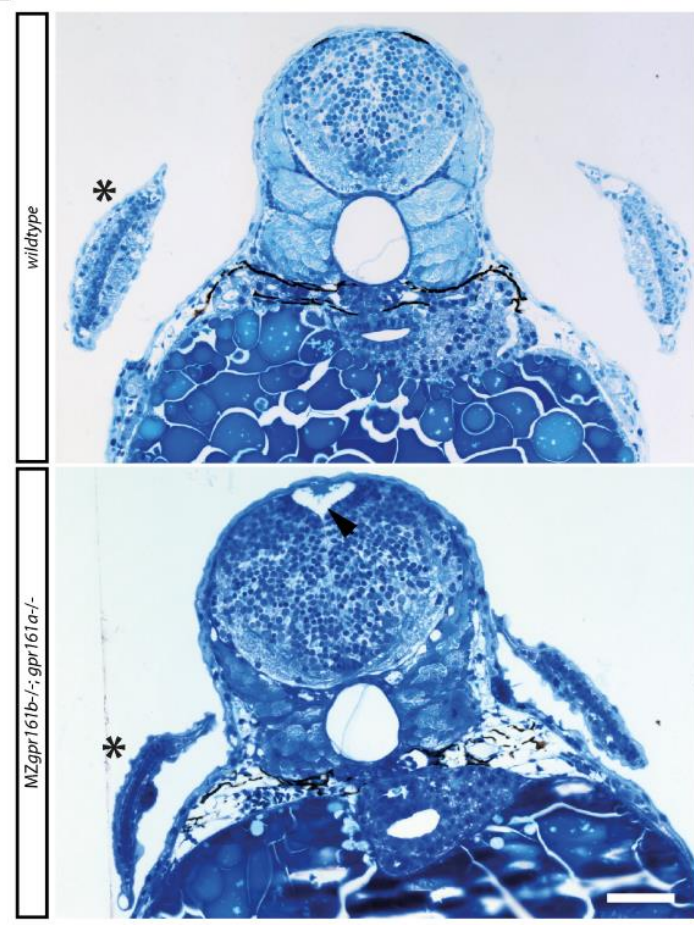

Figure 2-Supplement 2. Severe morphological defects in gpr161 mutant embryos at $72 \mathrm{hpf}$. (A) Transverse section through the embryonic eye at $72 \mathrm{hpf}$, Retinal layers are indicated as follows: RPE - retinal pigment epithelium, ONL - outer nuclear layer, OPL - outer plexiform layer, INL - inner nuclear layer, IPL inner plexiform layer, GCL ganglion cell layer. Inset shows remnant of a forming lens from a different section of the same gpr161 mutant embryo. (B) Transverse section through the embryonic eye of a $72 \mathrm{hpf}$ gpr161 mutant embryo shows a conspicuous invagination of the outer retinal layers. (C) Transverse section through the otic capsule of wildtype and gpr161 mutant embryos at $72 \mathrm{hpf}$. Asterisk highlights central canal and dorsolateral septum which are missing in gpr161 mutant embryos. Arrowhead shows otholits. (D) Transverse section through the hindbrain region of wildtype and gpr161 mutant embryos at $72 \mathrm{hpf}$. Asterisks highlight presence of pectoral fins. Arrowhead shows enlarged brain ventricle. An increase in hindbrain diameter can be noted. (all scale bars: $50 \mu \mathrm{m})$ 
bioRxiv preprint doi: https://doi org/10.1101/616482; this version posted April 23,2019 . The copyright holder for this preprint (which was not certified by peer review) is the author/funder, who has granted bioRxiv a license to display the preprint in perpetuity. It is made available under aCC-BY 4.0 International license.
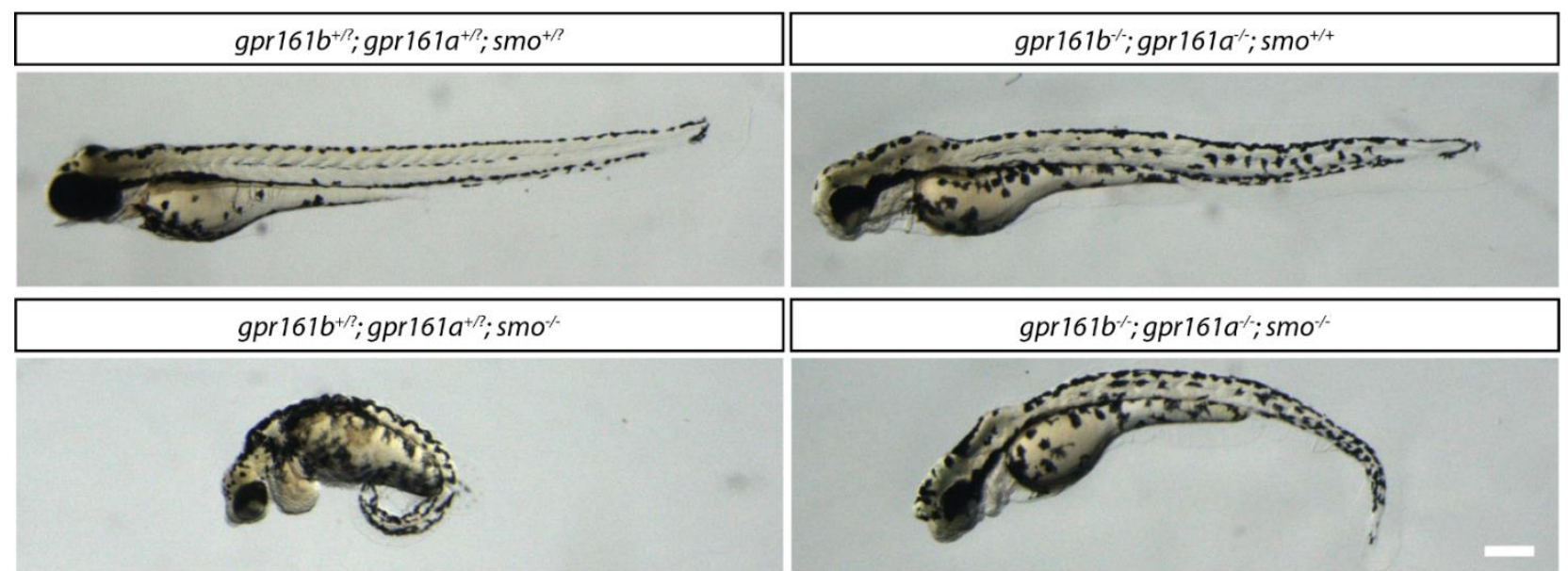

621 Figure 6-Supplement 1. Morphological phenotypes of $g$ pr161 $\mathrm{b}^{-/} ; \mathrm{gpr} 161 \mathrm{a}^{\circ /}$ mutants are independent of Smo. Lateral

622 view of embryos from a gpr161b+/; gpr161a ${ }^{+/-;}$smo $^{+/-}$incross at $72 \mathrm{hpf}$ (scale bar: $100 \mu \mathrm{m}$ ). 


\section{Tables}

624

Table 1. List of Antibodies

\begin{tabular}{|l|l|l|l|}
\hline Antibody & Source & Dilution & Identifier \\
\hline Prox1 & abcam & $1: 500$ & ab209849 \\
\hline Engr & DSHB & $1: 20$ & 4D9 \\
\hline Myc & abcam & $1: 500$ & ab9106 \\
\hline acTub & Sigma & $1: 500$ & T7451 \\
\hline Alexa Fluor 647 anti mouse & ThermoFisher & $1: 500$ & A-21235 \\
\hline Alexa Fluor 488 anti rabbit & ThermoFisher & $1: 500$ & A-11008 \\
\hline
\end{tabular}

626

Table 2. List of Primers

\begin{tabular}{|l|l|l|}
\hline Name & Used for & Sequence \\
\hline Gpr161a_SSLP_F & Genotyping & TGATCTGCACTGAGGCCTTATGGG \\
\hline Gpr161a_SSLP_R & Genotyping & AAGAGGATGACAAGCCGCACTG \\
\hline gpr161b_SSLP_F & Genotyping & CACAAGGGATTGATTGAAATG \\
\hline gpr161b_SSLP_R & Genotyping & ATTGCAAGCACAGCTCGATT \\
\hline gpr161a-IVA-F & Cloning & AATTCAAGGGCAAACATGAACACCAGCAGCAATGA \\
\hline gpr161a-IVA-R & Cloning & CACGGAGCCACCTCCTGCGCATATTTCCTCGATAT \\
\hline gpr161b-IVA-F & Cloning & AATTCAAGGGCAAACATGAACGGCTCTAAGAATGG \\
\hline gpr161b-IVA-R & Cloning & CACGGAGCCACCTCCCATTTTTTCCTCGCGCTCCA \\
\hline gli1_qpcr_f & qPCR & GTAAGGCCACACACACACTGATG \\
\hline gli1_qpcr_r & qPCR & GCTACACCCACAGTCCTCTTTG \\
\hline nkx2.2b_qpcr_f & qPCR & GTGCGGACACAAATATCCAGTGC \\
\hline nkx2.2b_qpcr_r & qPCR & ATCCGCGGACAGTTCTGGATTC \\
\hline nkx6.1_qpcr_f & qPCR & GACAGAGAGTCAAGTCAAGGTGTG \\
\hline nkx6.1_qpcr_r & qPCR & TCCTTTCAGCCTCTCGGTTTCTG \\
\hline olig2_qpcr_f & qPCR & TGCACCTGCTACCGGGAATATC \\
\hline olig2_qpcr_r & qPCR & TGTCAGAGTCCATGGCGTTCAG \\
\hline pax7a_qpcr_f & qPCR & ACGGCATTCTGGGAGACAAAGGTC \\
\hline pax7a_qpcr_r & qPCR & TGCGTCTCTGCTTTCTCTTGAGC \\
\hline eef1a1I1_qpcr_f & qPCR & TCTCTACCTACCCTCCTCTTGGTC \\
\hline eef1a1l1_qpcr_r & qPCR & TTGGTCTTGGCAGCCTTCTGTG \\
\hline rpl13a_qpcr_f & qPCR & ACAGGCTGAAGGTGTTTGATGGC \\
\hline rpl13a_qpcr_r & qPCR & GGACAACCATGCGCTTTCTCTTG \\
\hline gpr161b_qpcr_F & qPCR & ATAAGAGGAGGAGCTCGGTCAC \\
\hline gpr161b_qpcr_R & qPCR & TGGACTACTGAAGGGTCACCTTG \\
\hline gpr161a_qpcr_F & qPCR & AGCATCTCCAACCGAATCACAG \\
\hline gpr161a_qpcr_R & qPCR & CAACATGGTGTCTGTCCCTGAG \\
\hline
\end{tabular}

